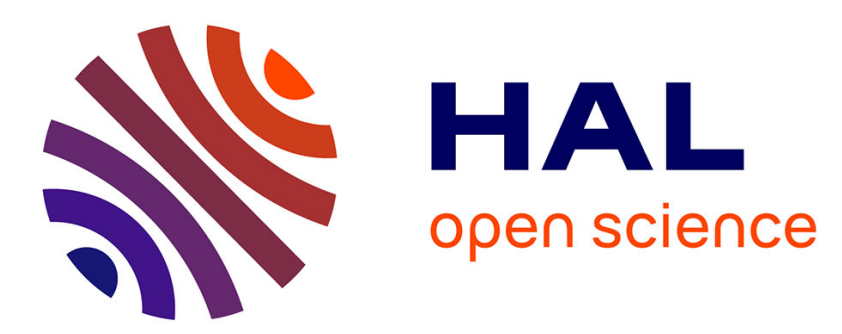

\title{
Modulation of Yorkie activity by alternative splicing is required for developmental stability
}

Diwas Srivastava, Marion de Toledo, Laurent Manchon, Jamal Tazi, François Juge

\section{- To cite this version:}

Diwas Srivastava, Marion de Toledo, Laurent Manchon, Jamal Tazi, François Juge. Modulation of Yorkie activity by alternative splicing is required for developmental stability. 2020. hal-03065221

\section{HAL Id: hal-03065221 \\ https://hal.science/hal-03065221}

Preprint submitted on 14 Dec 2020

HAL is a multi-disciplinary open access archive for the deposit and dissemination of scientific research documents, whether they are published or not. The documents may come from teaching and research institutions in France or abroad, or from public or private research centers.
L'archive ouverte pluridisciplinaire HAL, est destinée au dépôt et à la diffusion de documents scientifiques de niveau recherche, publiés ou non, émanant des établissements d'enseignement et de recherche français ou étrangers, des laboratoires publics ou privés. 


\section{Modulation of Yorkie activity by alternative splicing}

\section{is required for developmental stability}

Diwas Srivastava, Marion de Toledo, Laurent Manchon, Jamal Tazi \& François Juge*

Institut de Génétique Moléculaire de Montpellier, University of Montpellier, CNRS, Montpellier,

France

* Corresponding author (francois.juge@inserm.fr) 


\section{Abstract}

The mechanisms that contribute to developmental stability are barely known. Here we show that alternative splicing of yorkie (yki) is required for developmental stability in Drosophila. Yki encodes the effector of the Hippo pathway that has a central role in controlling organ growth and regeneration. We identify the splicing factor B52 as necessary for inclusion of yki alternative exon 3 that encodes one of the two WW domains of Yki protein. B52 depletion favors expression of Yki1 isoform carrying a single WW domain, and reduces growth in part through modulation of yki alternative splicing. Compared to the canonical Yki2 isoform containing two WW domains, Yki1 isoform has reduced transcriptional and growth-promoting activities, decreased binding to PPxYcontaining partners, and lacks the ability to bridge two proteins containing PPxY motifs. Yet, Yki1 and Yki2 interact similarly with transcription factors and can thus compete in vivo. Strikingly, flies deprived from Yki1 isoform exhibit increased fluctuating wing asymmetry, a signal of increased developmental noise. Our results identify yki alternative splicing as a new level of control of the Hippo pathway and provide the first experimental evidence that alternative splicing participates in developmental robustness. 


\section{Introduction}

The Hippo signaling pathway is a conserved pathway that regulates cell fate and cell proliferation to control organ growth and regeneration ${ }^{1}$. The core of the pathway comprises a kinase cascade including Hippo (Hpo, MST1/2 in mammals) and Warts (Wts, LATS1/2 in mammals), which phosphorylate the transcriptional coactivator Yorkie (Yki, YAP in mammals) to sequester it in the cytoplasm through binding to 14.3 .3 proteins. Upon inactivation of the pathway, unphosphorylated Yki/YAP translocates into the nucleus and activates a transcriptional program promoting cell proliferation and inhibiting apoptosis. Yki/YAP does not bind DNA directly but interacts with specific transcription factors, especially members of the TEAD family Scalloped (Sd) in flies and TEAD1/2/3/4 in mammals. Nuclear Yki/YAP then recruits the histone methyl-transferase NcoA6 to trigger transcription activation ${ }^{2,3}$. In addition, Yki was proposed to displace the transcriptional repressor Tgi (Tondu-domain-containing Growth Inhibitor, SDBP in mammals) from Sd/TEAD and relieve a transcriptional repression ${ }^{4,5}$. Yki/YAP interacts with its partners through different domains: the $\mathrm{N}$ terminal domain binds Sd/TEAD whereas the two WW domains mediate interaction with PPxY motifs-containing proteins such as the repressor Tgi and the transactivator NcoA6 for example. Interestingly, both Yki and YAP exist as two isoforms containing either one or two WW domains, owing to the alternative splicing of an exon encoding the second WW domain ${ }^{6,7}$. In mammals, YAP isoform with only one WW domain cannot bind angiomotin or p73 indicating that alternative splicing could play a role in the modulation of YAP activity ${ }^{8,9}$. Up to now, the molecular bases and as well as the functional importance of this alternative splicing event in vivo are unknown.

Here we identified $y k i$ as an alternative splicing target of the splicing factor B52 in Drosophila, and functionally address the importance of $y k i$ alternative splicing in vivo. The B52 protein belongs to the family of Serine and arginine-rich (SR) proteins that are conserved RNA binding proteins involved in several steps of mRNA metabolisms and which play a major role in both constitutive and alternative splicing ${ }^{10}$. We previously showed that, in Drosophila, the level of B52 protein influences cell growth ${ }^{11}$, but the underlying molecular mechanisms were not characterized. Here we show that 
B52 is necessary for inclusion of $y k i$ alternative exon and that B52's depletion reduces growth in part through modulation of $y k i$ alternative splicing. We further show that alternative inclusion of Yki second WW domain is an additional level of modulation of Yki activity that is unexpectedly required for correct growth equilibrium between right and left sides of Drosophila. These results identify the first alternative splicing event involved in developmental robustness.

\section{Results}

\section{$y k i$ alternative splicing is a target of B52}

We previously observed that B52 depletion reduces cell growth in Drosophila larvae salivary glands as well as in the thorax at later stages ${ }^{11}$. We reasoned that B52's effect on growth might be due to alternative splicing modulation of one or several genes controlling growth. To identify splicing events that are robustly affected by B52 depletion, we crossed two previously published RNA-seq datasets corresponding to RNAi-mediated depletion of B52 in S2 cells compared to control cells ${ }^{12,13}$. We used MAJIQ (Modeling Alternative Junction Inclusion Quantification) ${ }^{14}$ to identify Local Splicing Variations (LSV) that vary more than $20 \%$ between control and B52 RNAi conditions, in both datasets (see Methods). This identified 108 high-confidence splicing events in 105 genes (Fig. 1a and Supplementary Table 1). Remarkably, 24 genes encode proteins that have direct or indirect interaction(s) with another protein in the list, thus identifying 11 protein complexes (Fig. 1b). This high number of complexes is highly significant $(p<2 e-5)$ and shows that B52 tends to co-regulate alternative splicing of genes encoding protein partners. GO term enrichment analysis of the 105 genes identifies "regulation of organ growth" and "positive regulation of growth" as the most enriched GO terms (Fig. 1c). Among them, three genes linked to Hippo pathway were identified: yorkie (yki), WW domain binding protein 2 (Wbp2) and Zyxin (Zyx). RNA-seq data indicate that B52 depletion promotes skipping of exon 3 in yki mRNA, the inclusion of exons 6 and 7 in wbp2 and the retention of last intron in Zyx (Supplementary Fig. 1). The functional consequences of these 
alternative splicing events are unknown. We focused our study on $y k i$ which encodes the effector of Hippo pathway.

The exon 3 of $y k i$ gene encodes one of the two WW domains of the protein. Alternative inclusion of this exon leads to production of two isoforms that we named Yki2 and Yki1 according to their number of WW domains (Fig. 1d). We confirmed by RT-PCR and western blotting that RNAiinduced depletion of B52 in S2R+ cells, or in larval wing discs, induces skipping of $y k i$ exon 3 and increases expression of Yki1 at the expense of Yki2 isoform (Fig. 1e,f). These results identify B52 as necessary for inclusion of $y k i$ exon 3 and expression of Yki2 isoform.

\section{B52 depletion reduces growth and Yki activity}

To test whether B52 depletion affects Yki activity, we monitored the expression of two reporter genes, ex-lacZ and diap-lacZ, which are direct targets of Yki. Expression of B52 RNAi in the posterior domain of the wing disc decreases the expression of the two reporter genes in this domain, reflecting a reduction of Yki activity (Fig. 2a). This goes along with a reduction of posterior domain size. These flies are not viable at $25^{\circ}$ but are partially viable at $18^{\circ} \mathrm{C}$ and show a net reduction of wing posterior domain size (Fig. 2b). Using this phenotype, we tested whether B52 interacts genetically with the Hippo pathway. Overexpression of Yki (UAS-Yki-V5, corresponding to long isoform ${ }^{15}$ ), as well as depletion of the kinases Hpo or Wts by RNAi, partially rescues the growth defect induced by B52 depletion (Fig. 2b,c). Therefore, increasing Yki activity antagonizes the effect of B52 depletion. Nevertheless, posterior domain size in these contexts remains smaller than the corresponding controls (overexpression of Yki or depletion of Wts or Hpo in the absence of B52 depletion, Fig. 2c). This suggests that B52 depletion affects other genes or pathways necessary for efficient growth. Moreover, the strong overgrowth induced by Yki overexpression, or by Hpo or Wts depletion, may compensate a growth defect in B52 depleted cells, unrelated to the Hippo pathway. This is unlikely because depletion of Tgi, a transcriptional repressor interacting with $\mathrm{Sd}$, which induces a very mild increase of posterior domain size on its own, also rescues the growth defect due to B52 depletion 
(Fig. 2b,c). Altogether these results indicate that B52 depletion reduces growth at least in part through the Hippo pathway and suggest that it lowers Yki activity by modifying alternative splicing of $y$ ki mRNAs. We therefore explored the functional differences between the two Yki isoforms.

\section{Yki1 is a weaker transcriptional activator than Yki2}

To compare the activity of Yki isoforms, we created V5-tagged UAS-Yki1 and UAS-Yki2 transgenic flies for GAL4-mediated overexpression, by site-specific integration. Compared to Yki2, overexpression of Yki1 isoform induces weaker overgrowth phenotypes in the posterior domain of wings (Fig. 3a) or in the eyes (see Fig. 5a). We analyzed the expression of Yki reporter genes ex-lacZ and diap-lacZ following Yki isoforms overexpression in the posterior domain of wing discs. Expression of both transgenes is moderately increased by Yki1 overexpression as compared to Yki2 overexpression (Fig. $3 b, c)$. We also analyzed the expression of a bantam miRNA sensor, the expression of which is inversely correlated to the level of ban miRNA that is a direct target of Yki. Yki1 induces a weaker decrease of ban-sensor expression than Yki2 isoform (Fig. 3c). Together these results show that Yki1 has a reduced activity compared to Yki2 in vivo.

\section{Absence of the second WW domain modifies the binding and bridging activities of Yki}

Yki1 and Yki2 isoforms differ respectively by the absence or presence of the alternative exon 3, which includes the second WW domain. Numerous studies have demonstrated that, in the context of Yki2 isoform, WW domains are required for interaction with several partners containing PPxY motifs such as Ex, Hpo, Wts, NcoA6, Wbp2 and Tgi ${ }^{2-6,16-18}$. The absence of one WW domain in Yki1 could reduce interaction with such partners. Moreover, binding of proteins that interact with the $\mathrm{N}$-terminal part of Yki, such as Sd or 14.3.3, may also be affected if the structure of the protein is modified by the absence of the domains encoded by exon 3 . It is therefore important to address these interactions in the context of full-length proteins and with a quantitative assay. To this end, we developed a dualluciferase co-Immunoprecipitation (co-IP) method in S2R+ cells inspired by the DULIP method ${ }^{19}$ 
described in mammalian cells. Our assay monitors co-IP between a bait protein fused to Flag-taggedFirefly Luciferase (FFL) and a prey protein fused to Renilla Luciferase (RL). Quantification of luciferases activities ratio after IP with anti-Flag antibodies gives a rapid and sensitive readout of the interaction between the bait and the prey (Fig. 4a). FFL-Yki1 and FFL-Yki2 were used as baits for interactions with thirteen known Yki partners fused to RL as preys (Fig. 4b). We used FFL as a control for non-specific interactions and quantified a normalized co-IP interaction (NcolP, see methods). By this approach, we detected significant interactions between Yki isoforms and all proteins tested, from modest co-IP with GAF, MAD and Cbt, to high and very high interactions for the other proteins. We found that both isoforms Yki1 and Yki2 interact similarly with the transcription factors Sd, MAD, Cbt and $\mathrm{Hth}$, the chromatin-associated factors GAF and Mor, and with 14.3.3 protein (Fig. 4c). These results show that interactions with these partners are not influenced by the domains encoded by $y k i$ exon 3. On the other hand, Yki1's interaction with Hpo, Wts, Ex, NcoA6, Wbp2 and Tgi, which all contain PPxY motif(s), is reduced compared to Yki2 (Fig. 4c). Interestingly, the strength of this decrease correlates with the number of PPxY motifs present in these proteins (Fig. 4c). This is in agreement with in vitro studies reporting cooperative binding between multiple PPxY motifs and tandem WW domains of YAP and Yki ${ }^{20,21}$. Altogether, these results indicate that Yki isoforms interact similarly with transcription factors but that Yki1 cannot efficiently recruit co-activators like NcoA6 or Wbp2 to stimulate transcription.

In addition to increasing the binding of proteins with multiple PPxY motifs, the presence of two WW domains may also allow Yki2 to interact simultaneously with two PPxY-containing proteins. To test this hypothesis, we compared the ability of Yki isoforms to bridge different proteins, by monitoring their co-IP using our assay. Previous reports showed that Yki binds to Sd through its Nterminal part and to Tgi via the WW domains ${ }^{22,23}$. Moreover, Sd and Tgi were shown to interact directly ${ }^{4,5}$. Yki was shown to compete with Tgi for Sd binding ${ }^{4,5}$, but was also found in a trimeric complex with Sd and $\mathrm{Tgi}^{4}$. We, therefore, monitored Sd/Tgi interaction in absence or presence of Yki isoforms in transfected cells (Fig. 4d). Using FFL-Sd as bait, we detected co-IP between FFL-Sd and 
Tgi-RL in the absence of Yki. Both Yki1 and Yki2 isoforms enhanced the co-IP between Sd and Tgi, with Yki2 having a stronger effect. Point mutations in the two WW domains of Yki2 abolish this effect. These results are in agreement with the existence of a trimeric complex between Sd, Tgi and one isoform of Yki.

To further test Yki's bridging activity, we analyzed the co-IP between FFL-Sd and RL-Wbp2 by the same approach. The co-transfection of Yki1 or Yki2 increases the pull-down between Sd and Wbp2, with Yki2 having a stronger effect. Mutation of both WW domains in Yki2 abrogates this effect (Fig. 4e). These results indicate that, in interaction with Sd, both Yki1 and Yki2 isoforms participate in the recruitment of Tgi or Wbp2, with Yki2 being more efficient owing to its two WW domains. Finally, we tested if the two WW domains of Yki2 can interact with two different proteins carrying PPxY motifs. To this end, we analyzed the co-IP between Tgi and Wbp2 using FFL-Tgi as bait and RL-Wbp2 as prey. Remarkably, Yki2 isoform allowed to pull-down Wbp2 with Tgi, whereas Yki1 isoform did not. As expected, mutation of the two WW domains in Yki2 abrogates the co-IP (Fig. 4f). Altogether these results show that the presence of the second WW domain in Yki2 isoform increases the interactions with PPxY-motifs containing proteins and allows Yki2 to bridge two different proteins with such motifs.

\section{Yki isoforms can compete with each other in the nucleus}

Our results show that, compared to Yki2 isoform, Yki1 isoform interacts similarly with the transcription factors, but less with the transcription coactivators NcoA6 and Wbp2, providing an explanation to its lower transcriptional activity. This suggests that Yki isoforms may compete with each other for binding to the transcription factors. To directly test whether Yki1 isoform can compete with Yki2 isoform in vivo, we co-overexpressed them in the eye. We used wild-type forms of Yki isoforms as well as activated versions of these isoforms, carrying the mutation S168A that kills a Wts phosphorylation site and lowers Yki cytoplasmic retention by 14.3 .3 proteins ${ }^{24}$. We verified that this mutation favors the nuclear accumulation of both $\mathrm{Yki}^{\mathrm{S} 168 \mathrm{~A}}$ and $\mathrm{Yki}^{\mathrm{S} 168 \mathrm{~A}}$ isoforms (Supplementary Fig. 
2) and increases the overgrowth phenotypes induced by overexpression of these isoforms in the eye

(Fig. 5a). Of note, activated Yki1 ${ }^{\mathrm{S168A}}$ induces dramatically weaker overgrowth compared to $\mathrm{Yki}^{\mathrm{S168A}}$ confirming its reduced transcriptional activity. Overexpression of Yki2 ${ }^{5168 \mathrm{~A}}$ in the eye induces strong over-growth and remarkably, co-overexpression of activated Yki1 ${ }^{\mathrm{S168A}}$, but not non-activated form Yki1, reduces this phenotype (Fig. 5b), providing evidence of competition between the two isoforms in the nucleus. Altogether, our results are in agreement with a competition model between a fully active isoform Yki2 and a less-active isoform Yki1.

\section{B52's effect on growth involves yki alternative splicing}

Our results show that B52 depletion reduces growth (Fig. 2) and promotes expression of Yki1 isoform through modulation of $y k i$ alternative splicing (Fig. 1). To directly determine if this contributes to the effect of B52 on growth, we abrogated alternative splicing of $y k i$ exon 3 by creating flies producing exclusively Yki2 isoform. To this end, we edited endogenous $y k i$ locus to replace the central part of the gene by a portion of $y$ ki2 cDNA, therefore eliminating the introns surrounding exon 3 (Fig. 6a, see strategy in Supplementary Fig. 3). We generated two $y k i^{2-o n l y}$ alleles, $y k i^{2-o n l y-A}$ and $y k i^{2-o n l y-B}$, corresponding to two independent gene conversion events, which show identical phenotypes. Homozygous $y k^{2-o n l y}$ flies are viable, despite the fact that $y k i^{2-o n l y}$ embryos display about $50 \%$ lethality (not shown). We confirmed by western blotting that $y k^{2-o n l y}$ flies express only Yki2 isoform and do not produce Yki1 isoform (Fig. 6b). Remarkably, depletion of B52 in wing posterior domain in $y k^{2-o n l y}$ background induces a weaker phenotype than in a wild type background (Fig. 6 c) indicating that B52's effect on growth is in part due to modulation of $y k i$ alternative splicing.

Since Yki1 is less active than Yki2 isoform (Fig. 3) and can compete with it (Fig. 5), we asked whether the absence of Yki1 would lead to growth advantage. We did not detect overgrowth in $y k i^{2-}$ only adult flies. Therefore, we addressed if absence of Yki1 isoform influences growth in clonal assays in the wing disc. In this assay, wild-type sibling cells generated by mitotic recombination give rise to clones of similar size (Fig. $6 \mathrm{~d}$ ). On the other hand, homozygous $y k i^{2-o n l y-A}$ cells, obtained by mitotic 
recombination in heterozygous $y k^{2-o n l y-A} / y i^{+}$larvae, often create bigger clones than their sibling wild type $y k i^{+} / y k i^{+}$cells (Fig. 6e). In few cases, $y k i^{+} / y k i^{+}$sibling clones were not recovered, suggesting that these cells were eliminated. These results indicate that the absence of Yki1 in $y k i^{2-o n l y}$ cells increases overall Yki activity and are in agreement with a model of Yki1 isoform acting as a dimmer of Yki activity.

\section{Alternative splicing of $y k i$ is required for developmental stability}

Despite being viable and fertile, we noticed that several $y k^{2-o n l y}$ flies in the population display asymmetric wings (Fig. 7a). We measured fly wings areas of wild type and $y k^{2-o n l y}$ flies, in duplicate to take into account the variability introduced by the manual quantification. This measurement error is low compared to the size difference between right and left wings (Supplementary Fig. 4). The Fig. 7b illustrates the distribution of right and left wing sizes of 40 male and female flies in wild type flies and in the two $y k i^{2-o n l y}$ lines. We noticed an overall reduction of wing size in $y k i^{2-o n l y}$ flies compared to wild type, and an increased difference between right and left sides in several individuals. To quantify the asymmetry between left and right wings, we calculated the fluctuating asymmetry (FA) index FA10 ${ }^{25}$ which takes into account measurement errors. We observed that $y k i^{2-o n l y}$ flies display higher FA in both males and females than wild type controls (Fig. 7c). The intra-individual variation between the size of right and left wings is recognized as a readout of developmental instability ${ }^{26}$. These results indicate that $y k i$ alternative splicing is necessary for proper growth equilibration between sides during development. This is, to our knowledge, the first experimental evidence that alternative splicing participates in the maintenance of developmental stability.

\section{Discussion}

Here we show that alternative splicing of $y k i$ exon 3 represents an additional layer of modulation of Yki activity, that unexpectedly participates in buffering developmental noise. We identify the SR protein B52 as the first modulator of $y k i$ alternative splicing. Significantly, depletion of B52 reduces 
growth in the wing, and this phenotype is partially rescued in $y k^{2-o n l y}$ flies, indicating that B52's effect on growth is in part mediated by its influence on $y k i$ alternative splicing. B52 depletion induces skipping of $y k i$ exon 3 and favors the expression of the Yki1 isoform which is a weaker transcriptional activator, compared to the canonical Yki2 isoform. We demonstrate that Yki isoforms interact similarly with transcription factors but differ by their capacity to bind and bridge PPxY-containing proteins. Indeed, Yki1 isoform, which lacks the second WW domain, has reduced interactions with PPXY-containing proteins and lacks the ability to bridge two proteins containing PPxY-motifs. These observations allow us to propose the following model (Fig. 8). Upon repression of the Hippo pathway, unphosphorylated Yki isoforms enter the nucleus. In a wild type situation (Fig. 8a), Yki2 being more abundant, it joins the transcriptionally repressed Tgi-Sd complex. Within this trimeric complex, Yki2 may engage only one WW domain with Tgi, thus being able to recruit through the second WW domain another partner such as Wbp2 or NcoA6, which finally may, or not, displace Tgi. This could reconcile the observation that Tgi enhances Sd-Yki interaction but decreases distance between Sd and Yki as measured by FRET ${ }^{4}$ suggesting remodeling of the complex. In a context where B52 is depleted (Fig. 8b), Yki1 isoform level is increased and this isoform competes with Yki2. In a complex with Sd and Tgi, Yki1 would be unable to recruit additional partners and activate transcription, unless Tgi leaves the complex and free the single WW domain. Our results argue that a proper balance between Yki1 and Yki2 isoform is necessary, since abrogation of $y k i$ alternative splicing increases developmental instability (Fig. 8c). Somehow surprisingly, despite the fact that $y k i^{2-}$ only cells show growth advantage in clonal assays, $y k i^{2-o n l y}$ flies do not show overgrowth of the wings. It has been shown that, in addition to its intrinsic effect on tissue growth, Yki is involved in systemic growth by interacting with ecdysone signaling. Yki is involved in basal expression of ecdysone ${ }^{27}$, and interacts with the ecdysone receptor coactivator Taiman ${ }^{28}$. Alteration of ecdysone signaling in $y k i^{2-}$ only flies may contribute to the observed growth defects. In addition, it has recently been shown that Yki controls the expression of the Dilp8 hormone which is involved in inter-organ coordination of growth ${ }^{29}$. Strong Dilp8 mutants were shown to display high FA ${ }^{30}$. Significantly, genomic deletion of 
dilp8 Hippo Responsive Element is sufficient to increases FA in flies ${ }^{29}$ indicating that Yki's control on dilp8 is required to minimize developmental variability. It is possible that abrogation of $y k i$ alternative splicing alters Yki activity and its control on dilp8 expression, thus triggering instability. Nevertheless, we rarely detect upregulation of dilp8 expression in $y \mathrm{ki}^{2-o n l y}$ clones compared to wild type clones suggesting that this modulation is weak or occurs in only a small fraction of the clones (not shown). It is likely that the effects observed in $y k i^{2-o n l y}$ animals are a combination of local and global perturbations of growth signals. It will be important to determine to which extent $y k i$ alternative splicing is dynamically regulated during normal growth and regeneration, and which signals control this regulation. The splicing factor B52 is a prime candidate to be involved in this process.

Alternative splicing of pre-messenger RNAs is recognized as a major source of transcriptomic and proteomic diversity ${ }^{31,32}$. Its extent correlates with organism complexity ${ }^{33}$ and several examples illustrate that alternative splicing is a source of phenotypic novelty during evolution ${ }^{34}$. Here we provide an experimental evidence that alternative splicing also participates in the process of canalization, which reflects the resistance of a phenotype to genetic and/or environmental perturbations ${ }^{35}$. Indeed, abrogating a single alternative splicing event in the genome, in the $y k i$ gene, is sufficient to increase developmental instability in Drosophila. It has been proposed that alternative splicing networks created by some splicing regulators participate in the maintenance of transcriptome stability ${ }^{36}$. In this view, it is worth noting that B52 tends to control alternative splicing events in genes encoding protein partners. A similar observation was made for the neuronal-specific splicing factor Nova, which modulates alternative splicing of genes encoding protein that interact with one another ${ }^{37}$. Such co-regulation could be an efficient strategy to control the activity of specific protein complexes and to maintain cell homeostasis. It is therefore tempting to speculate that master regulators of alternative splicing networks also participate to developmental stability.

Our results highlight $y k i$ alternative splicing as a new level of modulation of Yki activity. It is worth noting that the alternative inclusion of the second WW domain is a conserved feature between Drosophila Yki and human YAP, whereas some characteristics of these proteins, such as the 
presence of a coiled-coiled domain and a PDZ domain in YAP, are not conserved between the two species. The second WW domain of Yki/YAP appears to reside in a separate exon since the emergence of bilaterians ${ }^{38}$, suggesting that alternative splicing of this exon could be an ancestral mode of modulation of Yki/YAP activity. Analogously to our results in flies, human YAP isoform containing a single WW domain (YAP1) is a weaker transcriptional activator than the YAP2 isoform containing two WW domains ${ }^{7}$. YAP activity is frequently upregulated in cancer cells ${ }^{39}$. Therefore, targeting this alternative splicing event to favor skipping of the alternative exon could be a novel strategy to lower YAP activity.

\section{Methods}

\section{RNA-seq analysis}

We used MAJIQ (Modeling Alternative Junction Inclusion Quantification) software (v1.0.7) to identify Local Splicing Variations (LSV) in two previously published datasets from Bradley et al. (2015) (\#GSM1552264, \#GSM1552267) and Brooks et al. (2015) (\#GSM627333, \#GSM627334 and \#GSM627343). Each dataset contains two replicates of control and B52-depleted cells RNA-seq. The reads were subjected to standard quality control (QC) and filtered according to the following parameters: (1) trimming and cleaning reads that aligned to primers and/or adaptors, (2) reads with over $50 \%$ of low-quality bases (quality value $\leq 15$ ) in one read, and (3) reads with over $10 \%$ unknown bases ( $\mathrm{N}$ bases). We used Trimmomatic software (v0.36) to remove primers and bad quality reads. After filtering, we removed short reads $(<36 \mathrm{bp})$, the remaining reads are called "clean reads" and stored as FASTQ format. Reads were aligned to Drosophila melanogaster reference genome release 6.19 using STAR (Spliced Transcripts Alignment to a Reference) software (v2.5.4b). STAR outputs were stored in BAM files. BAM files were then submitted to MAJIQ analysis pipeline. LSV definitions were generated and quantified by MAJIQ. MAJIQ applies several normalization factors to the raw values before to compute normalized PSI (Percent Selected Index) and compare them between replicates. To make a selection of best candidate genes we used a $\triangle \mathrm{PSI}$ threshold of 0.2 . All others 
parameters were used with default values. Gene and PSI lists for each dataset were compared to identify common events between them. This identified 108 alternative splicing events in 105 genes that show reproducible change of alternative splicing upon B52 depletion. GO term analysis was performed with PANTHER (http://pantherdb.org/). Sashimi plots were created with IGV (Integrative Genomics Viewer, https://igv.org/). Protein-protein interactions within the 105 identified genes were tested using Molecular Interaction Search Tool (MIST; http://fgrtools.hms.harvard.edu/MIST/) using the high confidence threshold which retains only the interactions (direct or indirect) supported by several experimental methods ${ }^{40}$. The number of complexes identified was compared to the distribution of the number of complexes found in 50 sets of 105 random genes, which fits a Poisson distribution $(\lambda=2.36)$.

\section{Fly strains and Genetics}

Drosophila were maintained on standard cornmeal-yeast medium. Experiments were performed at $25^{\circ} \mathrm{C}$, except for the analysis of wing phenotype of flies expressing B52 RNAi under the control of $h h$ Gal4 that were performed at $18^{\circ} \mathrm{C}$, as mentioned in figure legends. Inducible RNAi lines used were UAS-IR-B52 (GD8690), UAS-IR-Wts (GD1563 and TRiP.HMS00026), UAS-IR-Hpo (TRiP.HMS00006), UAS-IR-Tgi (TRiP.HMS00981) and were previously validated in the literature.

UAS-Yki1 and UAS-Yki1 ${ }^{S 168 A}$ transgenes were constructed from $p U A S-Y k i-V 5-H i s$ and $p U A S-$

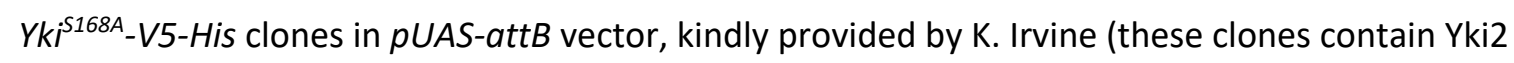
isoform cDNA). A Xhol site located between UAS sequences and start codon, flanked by two EcoRI sites, was deleted by EcoRI digestion and re-ligation of these vectors. This generated UAS-Yki2-V5-His

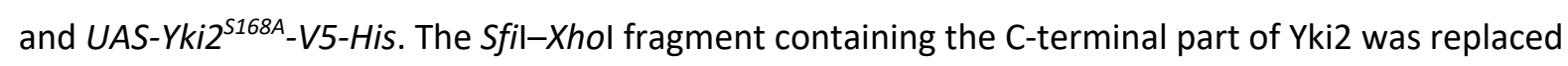
by the corresponding Sfil-Xhol amplified from a yki1 cDNA obtained by RT-PCR (third instar larvae). This generated UAS-Yki1-V5-His and UAS-Yki1 ${ }^{S 168 A}-$ V5-His transgenes. The four constructs UAS-Yki2V5-His, UAS-Yki2 ${ }^{\text {S168A }}$-V5-His, UAS-Yki1-V5-His and UAS-Yki1 ${ }^{\text {S168A }}$-V5-His were inserted in attP2 landing 
site through Phic31-mediated integration. Injections were performed by Bestgene Inc. In the text, UAS-Yki lines are named without the V5-His tag for simplicity.

For immuno-stainings, the following antibodies were used: mouse anti-ßGal (DSHB), mouse anti-V5 (Invitrogen) and rabbit anti-B52 ${ }^{41}$, using standard procedures. Images were acquired on a Leica SP5 confocal. To compare expression in anterior vs posterior part of wing discs, fluorescence intensity was quantified using OMERO (www.openmicroscopy.org) in an equivalent area in the anterior and posterior domains of the wing pouch, excluding dorso-ventral and anterio-posterior boundaries. For clonal analyses, larvae were heat shocked during $30 \mathrm{~min}$ at $37^{\circ} \mathrm{C}$, either $48 \mathrm{~h} \pm 4$ or $72 \mathrm{~h} \pm 4$ after egg laying, and then dissected $48 \mathrm{~h}, 68 \mathrm{~h}$ or $72 \mathrm{~h}$ after clone induction. Areas of clones were quantified in the wing pouch with OMERO.

The detail of genotypes used in each Figure is given in Supplementary Table 2.

\section{yorkie gene editing}

To edit endogenous $y k i$ locus by CRISPR/Cas9-mediated homologous recombination, a repair construct corresponding to $y k i$ gene without introns 2 and 3 , and containing a piggyBac insertion in intron 1, was created by cloning of multiple PCR fragments amplified with Q5-Taq polymerase (Biolabs). yki gene fragments were amplified from $y w$ flies. The piggyBac transposon containing the reporter gene 3xP3-DsRed (expresses DsRed in the eye), was amplified from $p H D-3 x F L A G-$ ScarlessDsRed (http://flycrispr.molbio.wisc.edu/scarless) (DGRC \#1367) and cloned into a Dral site present in $y k i$ intron 1 , thus creating TTAA sequences at both sides of the transposon that are necessary for its excision. We used two guide RNAs targeting exon 2 and exon 4 of $y k i$, cloned into pCFD4 (addgene \#49411). The plasmid containing the repair construct was co-injected with the plasmid encoding the two guides into nos-Cas9 embryos. Injection and screening for positive DsRED flies in the progeny were performed by Bestgene Inc. Two DsRED-positive lines, validated by PCR, were selected for excision of piggyBac transposon using a source of transposase (Bloomington \#8285). For each line a single excision event was selected to establish a stock. Two independent $y k i^{2-}$ 
only alleles were obtained, called $A$ and $B$. The entire $y k i$ locus was sequenced in these lines. We detected polymorphism in introns and silent polymorphism in exons. These differences are present between the $y w$ line used to create the $y k^{2-o n l y}$ construct and the nos-Cas9 line in which the injections were made. Both $y k i^{2-o n l y}$ lines gave similar results.

\section{Molecular biology}

cDNAs corresponding to MAD, GAF, Sd, Hth, 14.3.3, Hpo and Wbp2 were amplified from third instar larvae RNA by RT-PCR, using a forward primer starting at ATG and reverse primer located just upstream (or sometimes including) the stop codon. Forward primer contains CACC sequence upstream from ATG to orient cloning in pENTR/D-Topo (Invitrogen). All cDNAs were entirely sequenced. Other cDNAs were Cabut (DmCD00765693, DNASU), Tgi (DmCD00765105, DNASU), Mor (Addgene \#71048), Ex (kindly provided by N. Tapon). NcoA6 was amplified from a plasmid kindly provided by K. Irvine.

For DUAL-luciferase co-IP, we developed three destination vectors for the Gateway system: pAct-Flag-Firefly-RfA, pAct-HA-Renilla-RfA, pAct-RfB-Renilla-HA. The luciferase-gateway cassettes from mammalian vectors pcDNA-Flag-Firefly-RfA, pcDNA5-HA-Renilla-RfA and pcDNA5-RfB-RenillaHA (kindly provided by E. Bertrand) were cloned between Kpnl and Nhel sites of $p A F W$ vector backbone (Drosophila Genomics Resource Center). cDNAs cloned into pENTR/D-Topo were transferred to the appropriate destination vector by LR recombination (Invitrogen). Mutation of the two WW domains were introduced in Yki2 cDNA cloned in pENTR/D-Topo with Q5 Site-Directed Mutagenesis Kit (Biolabs). The sequence WxxP in each WW domain was mutated into FxxA to abolish binding without strongly modifying its structure ${ }^{42}$.

\section{Cell culture and co-immunoprecipitations}

Drosophila S2R+ cells were maintained in Schneider's medium (Invitrogen) supplemented with $10 \%$ fetal bovine serum (Sigma), $50 \mathrm{U} / \mathrm{ml}$ penicillin and $50 \mu \mathrm{g} / \mathrm{ml}$ streptomycin (Invitrogen) at $27^{\circ} \mathrm{C}$. For 
B52 depletion, S2R+ cells were treated with a mix of two dsRNA (produced by in vitro transcription) targeting exon 2 and exon 9 of B52, for 72H. RNAs were extracted with trizol (Sigma). Proteins were prepared in urea buffer ( $63 \mathrm{mM}$ Tris $\mathrm{HCl}$ pH7.5, 2\% SDS, 5\% 2-mercaptoethanol, 8M urea). Primary antibodies used for western were: rabbit anti-Yki ${ }^{43}$, rat anti-B52 ${ }^{44}$, mouse anti-actin (DSHB).

For dual-luciferase co-IP, S2R+ cells were transfected with two plasmids ( $0.15 \mu \mathrm{g}$ each), in quadruplicate, in 24-wells plates (400000 cells/well) using effectene (Qiagen). Typically, 4 plates were handle at the same time to perform 24 co-IPs in quadruplicate. After $48 \mathrm{~h}$ of transfection, cells were

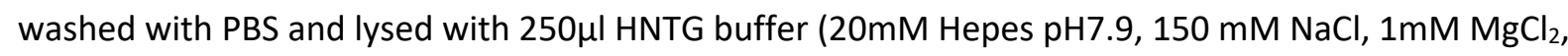
$1 \mathrm{mM}$ EDTA, 1\% triton, 10\% glycerol) supplemented with proteases inhibitors (Halt inhibitor cocktail, Thermo Scientific). Immunoprecipitation (IP) were performed on each lysate in 96-wells Neutravidin plates (Termo Scientific) previously coated for $2 \mathrm{~h}$ with biotinylated anti-Flag antibody (Bio-M2, Sigma) in HNTG (2 $\mu \mathrm{g}$ antibody/well). IP were performed with $100 \mu$ l of lysate/well and incubated overnight at $4^{\circ}$. IP were washed 5 times with $200 \mu \mathrm{HNTG} /$ well for $5 \mathrm{~min}$ at $20^{\circ}$ on a thermomixer (Eppendorf) with intermittent shacking. Firefly luciferase (FL) and Renilla luciferase (RL) activities were then quantified with DUAL luciferase reporter assay (Promega) using $50 \mu$ l of reagents/well and an InfiniteF200 reader (TECAN). To quantify input, 10 1 l of each lysate were transferred in a white 96 plate and quantified as the same time as IP plate with the same procedure. The level of co-IP is quantified by calculating the level of co-IP normalized to the efficiency of IP:

$\operatorname{colP}=\left(R L^{L P} / R L^{\text {Input }}\right) /\left(F L^{I P} / F L^{\text {Input }}\right)$. For each prey tested, a control co-IP using Flag-Firefly $(F F L)$ as bait was performed and used as reference (interaction set to 1). Each colP value was normalized to the mean of the quadruplicate control co-IP: NcolP = colPFFLbait/MEAN(colP FFL).

For bridging experiments between a FL-tagged bait and a RL-tagged prey, in absence or presence of Yki isoforms, the same procedure was used with a co-transfection of $0.15 \mu \mathrm{g}$ of Firefly

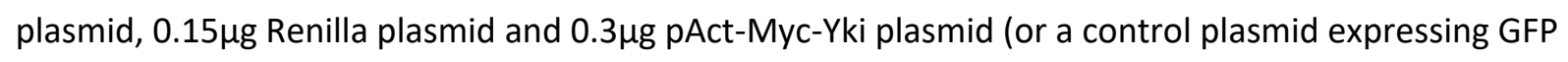
for control without Yki). Transfections and IPs were performed in quadruplicate as described above. Interaction detected in absence of Yki was used as reference to calculate the normalized co-IP ratio 
NcolP. In all co-IP, results represent mean \pm s.e.m. Student's t-tests (unpaired two-tailed) were performed using GraphPad Prism and illustrated as: * p-value $<0.05, * *$-value $<0.01, * * * p$ value $<0.001, * * * *$ p-value $<0.0001$

\section{Wing measurements}

For measurements of posterior vs total area (experiments with hh-Gal4 driver), young flies (1-3 days) of the appropriate genotypes were stored in isopropanol. Wings were mounted in Euparal (Carl Roth $\mathrm{GmbH}$ ) on glass slide with coverslip and baked overnight at $65^{\circ}$. Pictures were acquired on a Leica M80 stereomicroscope equipped with a Leica IC80 HD camera using LAS software. Measurements were performed with OMERO (www.openmicroscopy.org).

For quantification of Fluctuating Asymmetry (FA), L1 larvae of the appropriate genotypes were collected 24 to $28 \mathrm{~h}$ after egg laying and reared at 30 animals per tube at $25^{\circ} \mathrm{C}$. Corresponding adult flies were collected, stored in isopropanol and their left and right wings were mounted as pairs. Slides were digitalized using Nanozoomer (Hamamatsu). Measurements of wing areas were performed with ImageJ. Each wing was measured twice in two independent sessions, by one or two persons. In rare case where the variation between replicate measurements was superior to $0.5 \%$ of total wing area, the wing was quantified again to minimize measurement error. The FA10 index was used to estimate FA, i.e. FA corrected for measurement error, directional asymmetry and interindividual variation ${ }^{25}$. For all genotypes, the interaction individual/side was significant, indicating that FA was larger than measurement error (Supplementary Fig. 4). Conventional two-way mixed model ANOVAs were applied to areas data using GraphPad Prism Software. These values were used to calculate $F A 10$ index: $F A 10=\left(M_{\text {Interaction }}-\mathrm{MS}_{\text {Residual }}\right) / 2$. To compare $F A 10$ values between genotypes, we used F-test to compare variance of the samples.

\section{Acknowledgements}

We thank Nicolas Tapon for helpful comments on the manuscript and Thierry Gostan for his advices 
on statistical analyses. We thank Kenneth Irvine, Nicolas Tapon, Alexandre Djiane and Edouard Bertrand for sharing flies, constructs, and antibodies. We thank the Montpellier RIO Imaging facility for microscopy. We acknowledge the Bloomington Drosophila Stock Center for providing flies stocks, the Developmental Studies Hybridoma Bank (DSHB) for antibodies, and the Drosophila Genomics Resource Center (DGRC), DNASU and Addgene for plasmids. DS was supported by a PhD fellowship from la Ligue Nationale Contre le Cancer.

\section{Author contributions}

DS and FJ performed genetic experiments and wing quantifications. DS performed immunostainings and associated quantifications. MDT and FJ performed the experiments with S2 cells. LM performed the RNA-seq and splicing analyses. JT financed the project and participated into data analysis. FJ designed the project and wrote the manuscript.

\section{Competing interests}

The authors declare no competing interests.

\section{References}

1. Misra, J. R. \& Irvine, K. D. The Hippo Signaling Network and Its Biological Functions. Annu. Rev. Genet. 52, 65-87 (2018).

2. Qing, Y. et al. The Hippo effector Yorkie activates transcription by interacting with a histone methyltransferase complex through Ncoa6. Elife 3, 1260 (2014).

3. Oh, H. et al. Yorkie promotes transcription by recruiting a histone methyltransferase complex. Cell Rep 8, 449-459 (2014).

4. Guo, T. et al. A novel partner of Scalloped regulates Hippo signaling via antagonizing Scalloped-Yorkie activity. Cell Res. 23, 1201-1214 (2013).

5. Koontz, L. M. et al. The Hippo effector Yorkie controls normal tissue growth by antagonizing scalloped-mediated default repression. Dev. Cell 25, 388-401 (2013).

6. Huang, J., Wu, S., Barrera, J., Matthews, K. \& Pan, D. The Hippo signaling pathway coordinately regulates cell proliferation and apoptosis by inactivating Yorkie, the Drosophila Homolog of YAP. Cell 122, 421-434 (2005).

7. Komuro, A., Nagai, M., Navin, N. E. \& Sudol, M. WW domain-containing protein YAP associates with ErbB-4 and acts as a co-transcriptional activator for the carboxyl-terminal fragment of ErbB-4 that translocates to the nucleus. J. Biol. Chem. 278, 33334-33341 (2003). 
8. Oka, T., Schmitt, A. P. \& Sudol, M. Opposing roles of angiomotin-like-1 and zona occludens-2 on pro-apoptotic function of YAP. Oncogene 31, 128-134 (2012).

9. Oka, T., Mazack, V. \& Sudol, M. Mst2 and Lats kinases regulate apoptotic function of Yes kinase-associated protein (YAP). J. Biol. Chem. 283, 27534-27546 (2008).

10. Howard, J. M. \& Sanford, J. R. The RNAissance family: SR proteins as multifaceted regulators of gene expression. Wiley Interdiscip Rev RNA 6, 93-110 (2015).

11. Fernando, C., Audibert, A., Simon, F., Tazi, J. \& Juge, F. A Role for the Serine/Arginine-Rich (SR) Protein B52/SRSF6 in Cell Growth and Myc Expression in Drosophila. Genetics 199, 1201-1211 (2015).

12. Bradley, T., Cook, M. E. \& Blanchette, M. SR proteins control a complex network of RNAprocessing events. RNA 21, 75-92 (2015).

13. Brooks, A. N. et al. Regulation of alternative splicing in Drosophila by 56 RNA binding proteins. Genome Res. 25, 1771-1780 (2015).

14. Vaquero-Garcia, J. et al. A new view of transcriptome complexity and regulation through the lens of local splicing variations. Elife 5, e11752 (2016).

15. Oh, H. \& Irvine, K. D. In vivo analysis of Yorkie phosphorylation sites. Oncogene 28, 1916-1927 (2009).

16. Badouel, C. et al. The FERM-domain protein Expanded regulates Hippo pathway activity via direct interactions with the transcriptional activator Yorkie. Dev. Cell 16, 411-420 (2009).

17. Oh, H., Reddy, B. V. V. G. \& Irvine, K. D. Phosphorylation-independent repression of Yorkie in Fat-Hippo signaling. Dev. Biol. 335, 188-197 (2009).

18. Zhang, X., Milton, C. C., Poon, C. L. C., Hong, W. \& Harvey, K. F. Wbp2 cooperates with Yorkie to drive tissue growth downstream of the Salvador-Warts-Hippo pathway. Cell Death Differ. 18, 1346-1355 (2011).

19. Trepte, P. et al. DULIP: A Dual Luminescence-Based Co-Immunoprecipitation Assay for Interactome Mapping in Mammalian Cells. J. Mol. Biol. 427, 3375-3388 (2015).

20. Webb, C. et al. Structural features and ligand binding properties of tandem WW domains from YAP and TAZ, nuclear effectors of the Hippo pathway. Biochemistry 50, 3300-3309 (2011).

21. Nyarko, A. Differential Binding Affinities and Allosteric Conformational Changes Underlie Interactions of Yorkie and a Multivalent PPxY Partner. Biochemistry 57, 547-556 (2018).

22. Goulev, Y. et al. SCALLOPED interacts with YORKIE, the nuclear effector of the hippo tumorsuppressor pathway in Drosophila. Curr. Biol. 18, 435-441 (2008).

23. Zhang, L. et al. The TEAD/TEF family of transcription factor Scalloped mediates Hippo signaling in organ size control. Dev. Cell 14, 377-387 (2008).

24. Dong, J. et al. Elucidation of a universal size-control mechanism in Drosophila and mammals. Cell 130, 1120-1133 (2007).

25. Palmer, A. R. \& Strobeck, C. FLUCTUATING ASYMMETRY: Measurement, Analysis, Patterns. Ann. Rev. Ecol. Syst. 17, 391-421 (1986).

26. Palmer, A. R. in Developmental Instability Its Origins and Evolutionary Implications (ed. Markov, T. A.) 335-364 (1994).

27. Moeller, M. E. et al. Warts Signaling Controls Organ and Body Growth through Regulation of Ecdysone. Curr. Biol. 27, 1652-1659.e4 (2017).

28. Zhang, C. et al. The ecdysone receptor coactivator Taiman links Yorkie to transcriptional control of germline stem cell factors in somatic tissue. Dev. Cell 34, 168-180 (2015).

29. Boone, E., Colombani, J., Andersen, D. S. \& Léopold, P. The Hippo signalling pathway coordinates organ growth and limits developmental variability by controlling dilp8 expression. Nat Commun 7, 13505 (2016).

30. Garelli, A., Gontijo, A. M., Miguela, V., Caparros, E. \& Dominguez, M. Imaginal discs secrete insulin-like peptide 8 to mediate plasticity of growth and maturation. Science $336,579-582$ (2012).

31. Floor, S. N. \& Doudna, J. A. Tunable protein synthesis by transcript isoforms in human cells. Elife 5, 1276 (2016). 
32. Liu, Y. et al. Impact of Alternative Splicing on the Human Proteome. Cell Rep 20, 1229-1241 (2017).

33. Chen, L., Bush, S. J., Tovar-Corona, J. M., Castillo-Morales, A. \& Urrutia, A. O. Correcting for differential transcript coverage reveals a strong relationship between alternative splicing and organism complexity. Mol. Biol. Evol. 31, 1402-1413 (2014).

34. Bush, S. J., Chen, L., Tovar-Corona, J. M. \& Urrutia, A. O. Alternative splicing and the evolution of phenotypic novelty. Philos. Trans. R. Soc. Lond., B, Biol. Sci. 372, (2017).

35. WADDINGTON, C. H. CANALIZATION OF DEVELOPMENT AND THE INHERITANCE OF ACQUIRED CHARACTERS. Nature 150, 563-565 (1942).

36. Jangi, M. \& Sharp, P. A. Building robust transcriptomes with master splicing factors. Cell 159, 487-498 (2014).

37. Ule, J. et al. Nova regulates brain-specific splicing to shape the synapse. Nat. Genet. $\mathbf{3 7}, \mathbf{8 4 4 -}$ 852 (2005).

38. Hilman, D. \& Gat, U. The evolutionary history of YAP and the hippo/YAP pathway. Mol. Biol. Evol. 28, 2403-2417 (2011).

39. Zanconato, F., Cordenonsi, M. \& Piccolo, S. YAP/TAZ at the Roots of Cancer. Cancer Cell 29, 783-803 (2016).

40. Hu, Y. et al. Molecular Interaction Search Tool (MIST): an integrated resource for mining gene and protein interaction data. Nucleic Acids Res. 46, D567-D574 (2018).

41. Fic, W., Juge, F., Soret, J. \& Tazi, J. Eye development under the control of SRp55/B52-mediated alternative splicing of eyeless. PLoS ONE 2, e253 (2007).

42. Chen, H. I. et al. Characterization of the WW domain of human yes-associated protein and its polyproline-containing ligands. J. Biol. Chem. 272, 17070-17077 (1997).

43. Oh, H. \& Irvine, K. D. In vivo regulation of Yorkie phosphorylation and localization. Development 135, 1081-1088 (2008).

44. Juge, F., Fernando, C., Fic, W. \& Tazi, J. The SR protein B52/SRp55 is required for DNA topoisomerase I recruitment to chromatin, mRNA release and transcription shutdown. PLoS Genet. 6, e1001124 (2010). 

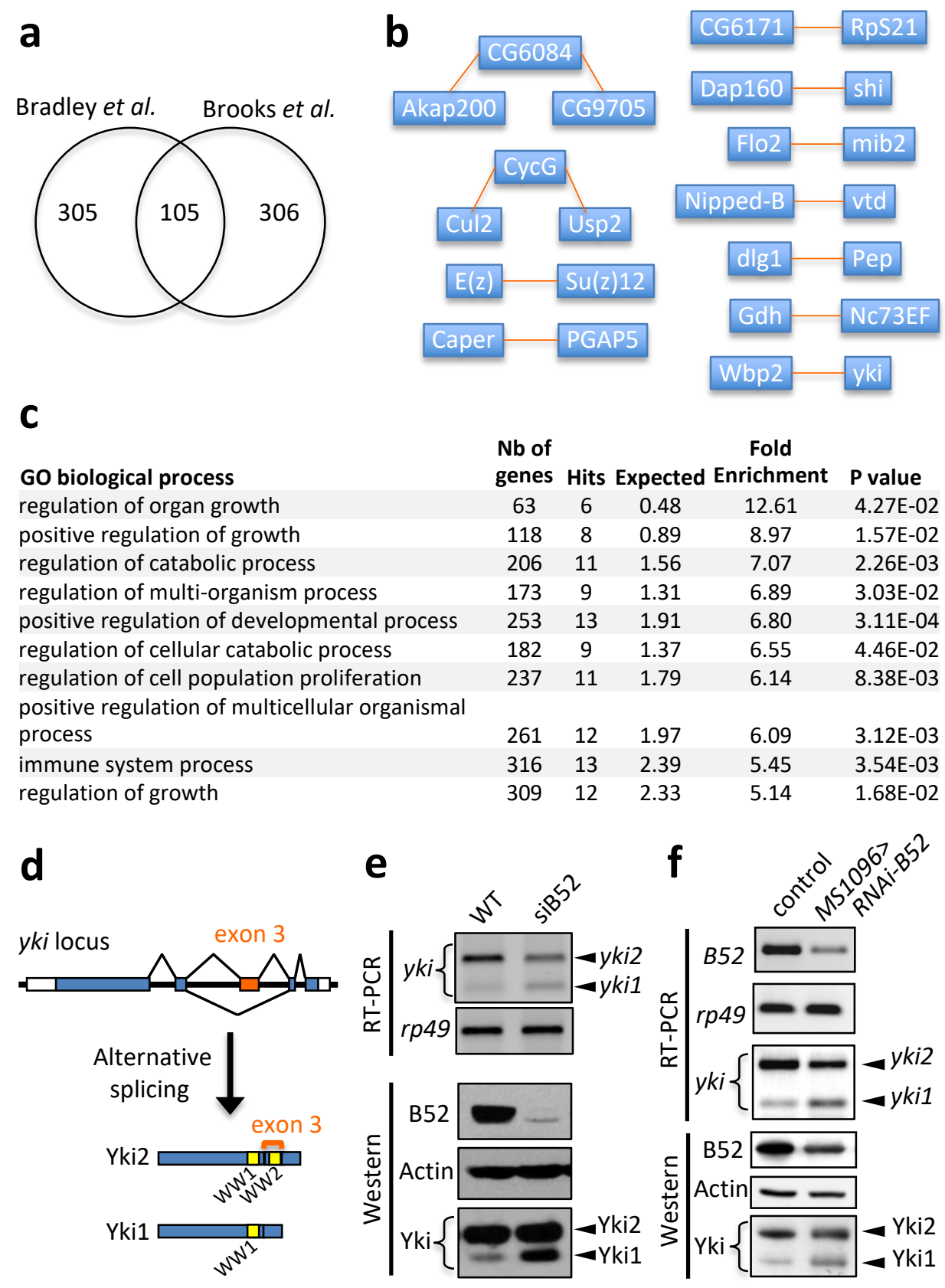

Fig. 1. Identification of $y k i$ as a B52-regulated alternative splicing target.

a, Number of genes identified by MAJIQ that display $20 \%$ or more variation in splicing between wildtype and B52 depleted cells, in each dataset. We identified 108 shared alternative splicing events, corresponding to 105 genes. A comprehensive list of the 108 events is given in Supplementary Table 1. b. High confidence protein-protein complexes identified by MIST (Molecular Interaction Search Tool) within the 105 genes identified in a. Interactions between proteins can be direct or indirect within the complexes. c, GO term enrichment analysis of the 105 genes identified in a, performed by PANTHER with Bonferroni correction for multiple testing. d, Drawing of $y k i$ locus and its two isoforms: Yki2 (includes exon 3 and contains 2 WW domains) and Yki1 (skips exon 3 and contains 1 WW domain). e,f, RT-PCR and western blot showing the effect of RNAi-mediated B52 depletion in S2R+ cells (e) and in larval wing discs (f). Note that for the wing discs, the Gal4 driver MS1096 is expressed only in the wing pouch of the disc, thus depletion is partial. 

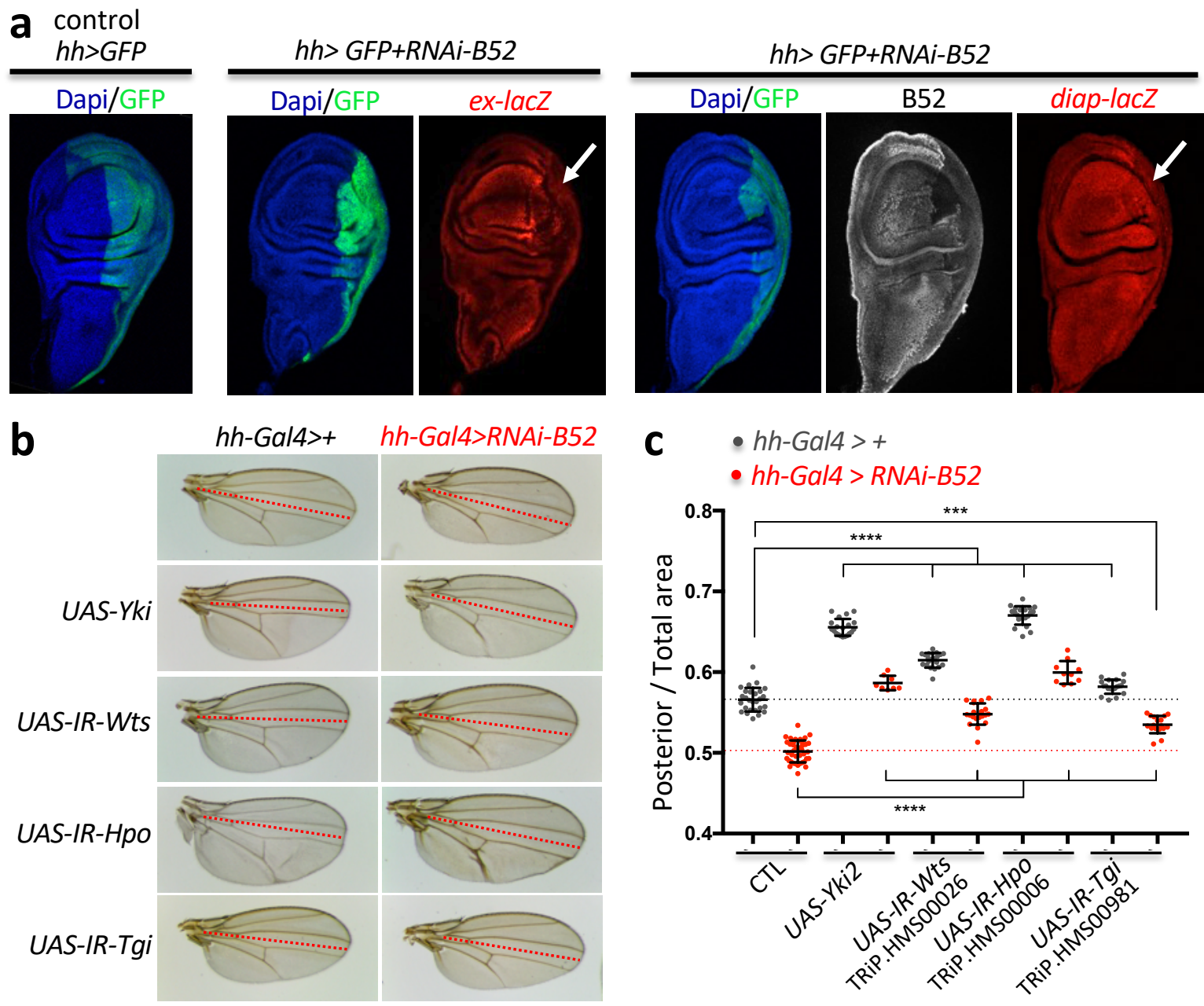

Fig. 2. B52 depletion lowers Yki activity and reduces growth.

a, Expression of diap-lacZ and ex-lacZ reporters upon depletion of B52 in the posterior part of the wing disc. $\mathbf{b}$, Wing phenotype induced by depletion of $B 52$ in the posterior domain of the wing disc (below dotted lines). Flies were grown at $18^{\circ} \mathrm{C}$. c, Quantification of Posterior/Total wing area in male flies. Each point represents a single wing, bars represent mean with standard deviation. ${ }^{* * *} \mathrm{p}$ value $<0.001, * * * * p$-value $<0.0001$ (unpaired two-tailed t-tests). Flies were grown at $18^{\circ} \mathrm{C}$. 
a

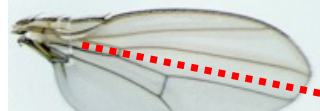

CTL

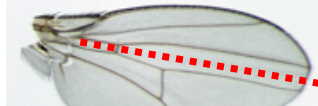

Yki1
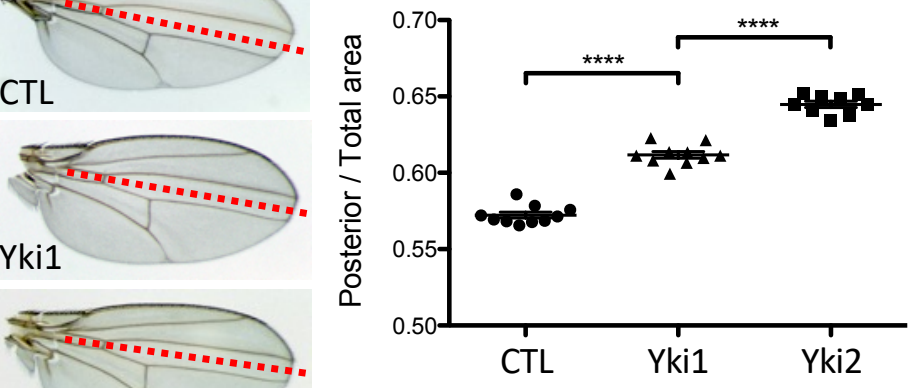

Yki2

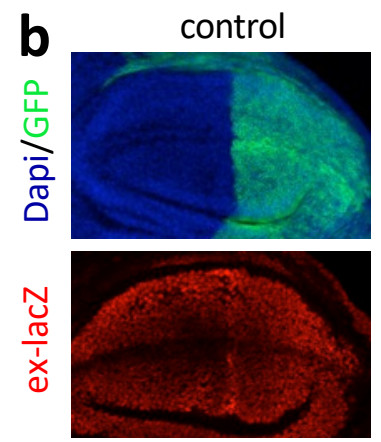

$h h-G a l 4>U A S-Y k i 1$

hh-Gal4>UAS-Yki2
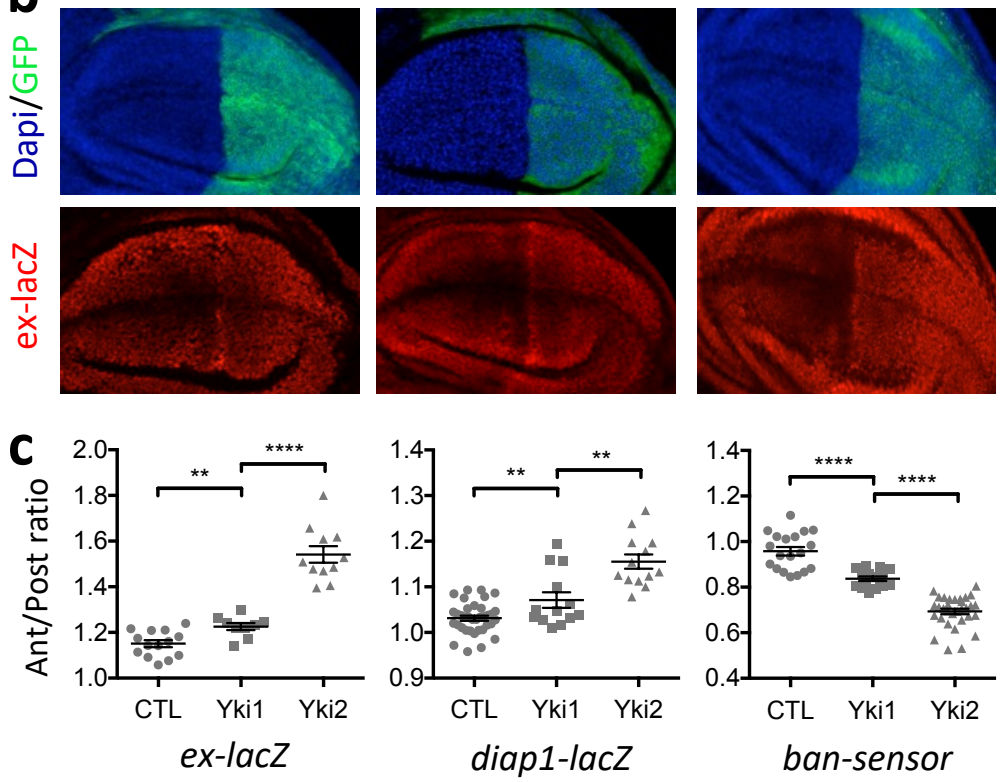

Fig. 3. Yki1 isoform is a weaker transcriptional activator than Yki2 isoform. a, Phenotype of wings overexpressing Yki1 or Yki2 in the posterior compartment ( $h h$-Gal4 driver), with the corresponding quantification of the ratio between posterior domain size and total wing size. $\mathbf{b}$, Example of immunostaining used to quantify expression of ex-lacZ in wild type or upon Yki1 or Yki2 overexpression in wing disc posterior domain. GFP labels the posterior domain. c, Quantification of Yki reporter genes expression upon overexpression of Yki isoforms in the wing posterior domain ( $h h$-Gal4 driver). For each target gene, relative expression between posterior and anterior domain in the wing discs was quantified by immunostaining using anti-ßggal antibody (for ex-lacZ and diap1-lacZ) or direct visualization of GFP (ban-sensor, in this case posterior domain was visualized by immunostaining against V5-tag present in UAS-Yki transgenes). In the scatter dot plot, each symbol (circle, square and triangle) represents a single wing disc, bars represent mean with SEM. ${ }^{* *} \mathrm{p}$-value $<0.01 ;{ }^{* * *} \mathrm{p}$-value $<0.0001$ (unpaired two-tailed t-tests). 

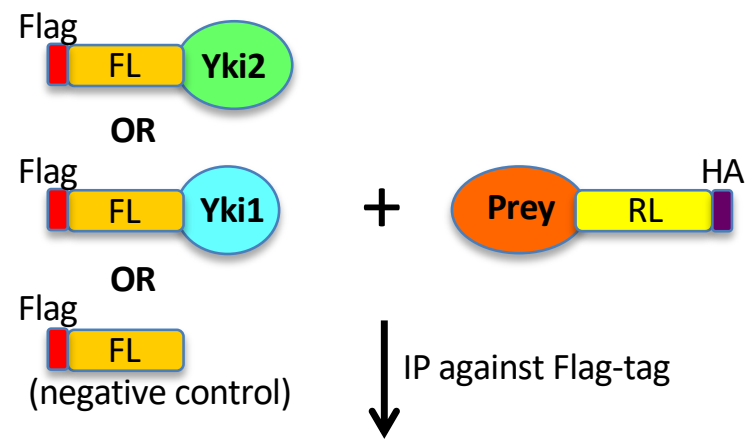

$$
\text { colP }=\frac{\frac{\mathrm{IPRL}}{\operatorname{Input} \mathrm{RL}}}{\frac{\mathrm{IPF}}{\operatorname{Input} \mathrm{FL}}}
$$

b

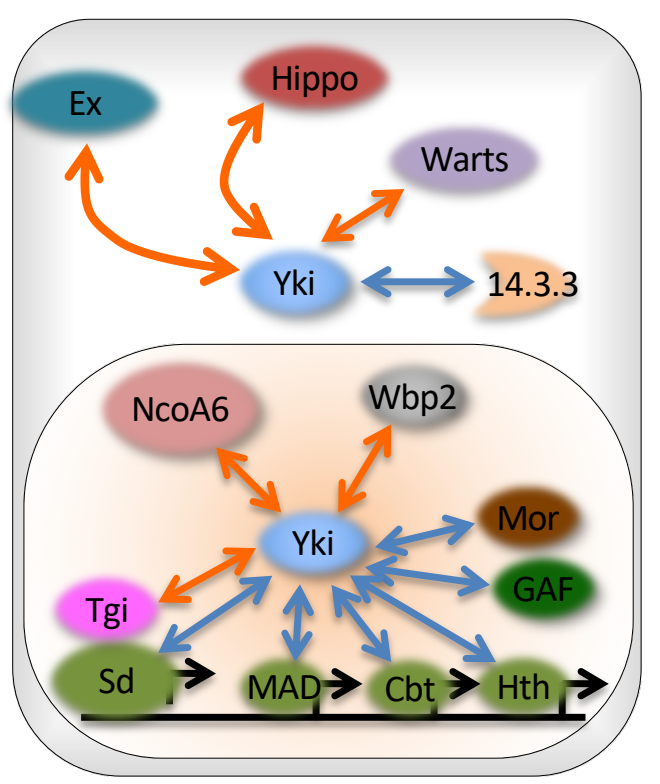

C
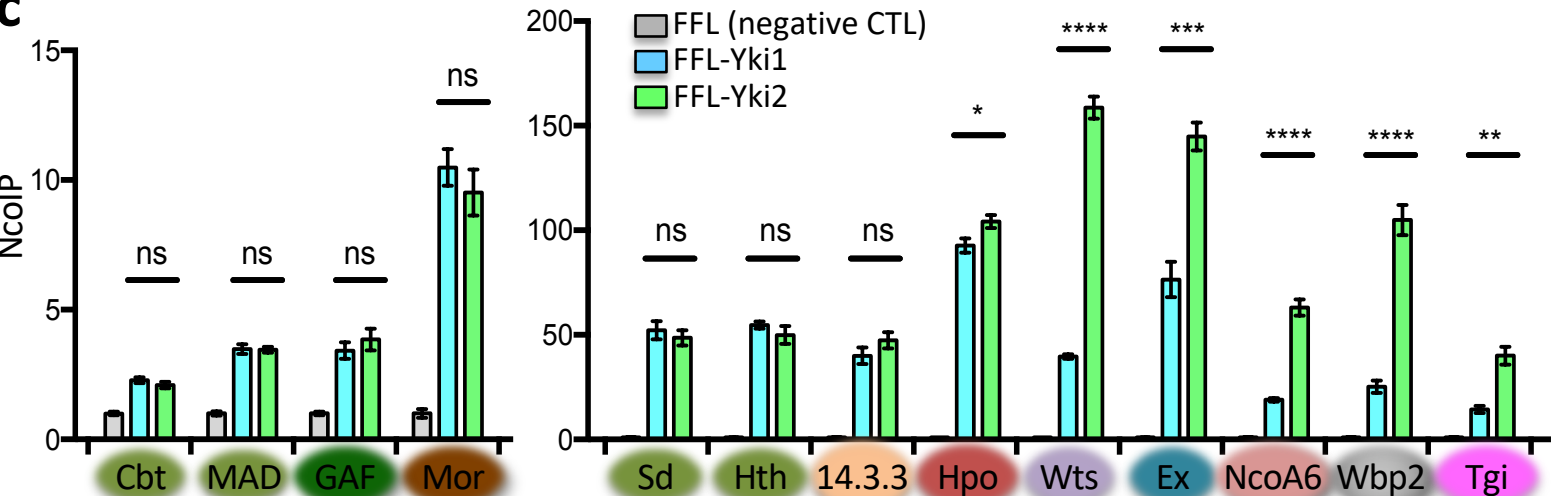

$\mathrm{Sd}$

Number of PPxY motifs

$\begin{array}{cc}1 & 5 \\ 10.9 & 74.9\end{array}$

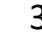

3

Decrease in binding (\%)
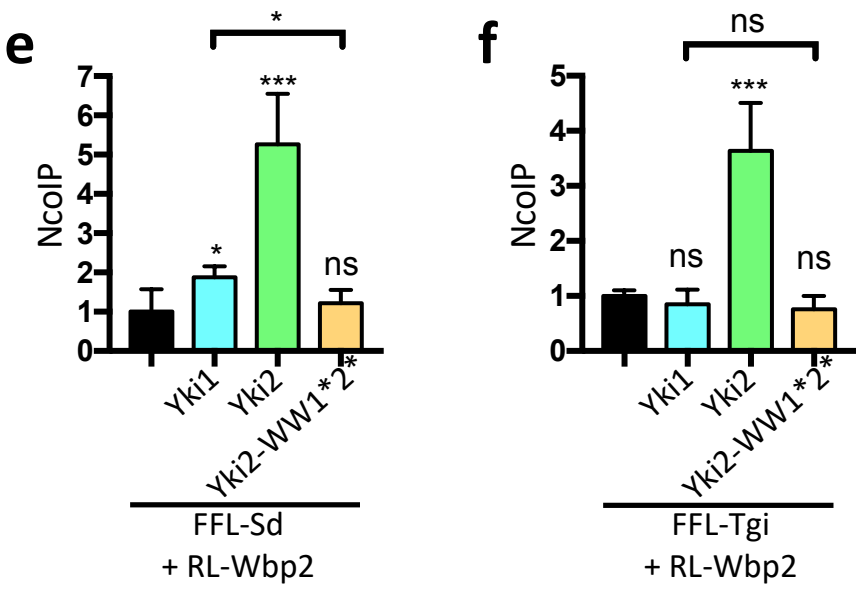

Fig. 4. Comparison of Yki isoforms binding properties.

a, Principle of dual-luciferase co-IP. In all experiments IP is performed against the Flag-tag fused to the Firefly Luciferase (FFL). FFL (unfused to Yki) is used as reference to normalize each interaction. The prey protein is fused to Renilla Luciferase (RL) in C-term for most proteins or in N-term (for Wbp2 and Mor). b, Drawing of the monitored protein-protein interactions. Interactions previously shown to involve WW domains are indicated by orange arrows, whereas other interactions are schematized by blue arrows. c, Comparison of Yki isoforms binding capabilities by dual-luciferase co-IP. Graphs show the normalized coIP (NcolP) results for 13 proteins tested against the two Yki isoforms and the negative control (FlagFirefly). d, Interaction between Sd and Tgi in absence or presence of Yki isoforms. e, Interaction between $\mathrm{Sd}$ and $\mathrm{Wbp} 2$ in absence or presence of Yki isoforms. $\mathbf{f}$, Interaction between Tgi and Wbp2 in absence or presence of Yki isoforms. 

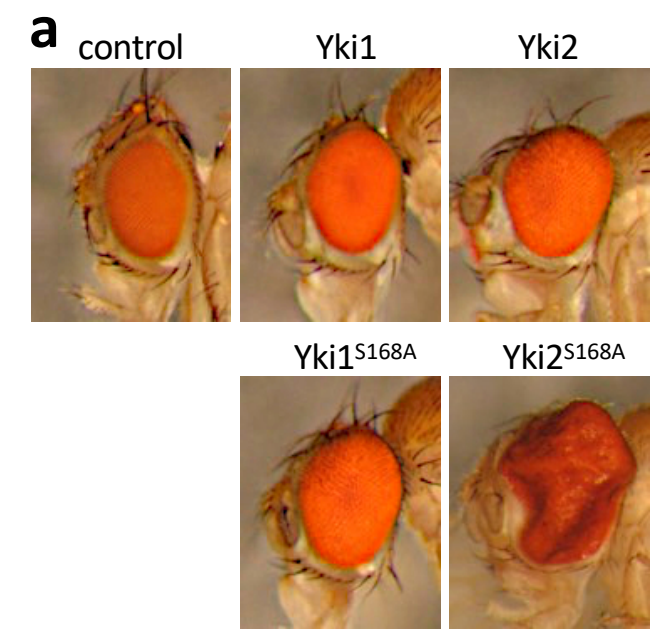

b

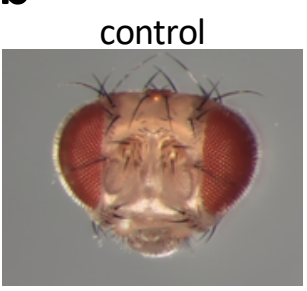

overexpression $\mathrm{Yki}^{\mathrm{S} 168 \mathrm{~A}}$

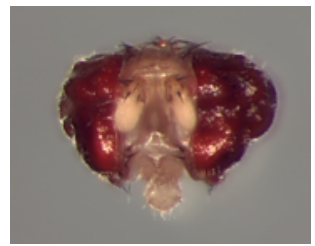

overexpression

overexpression

$\mathrm{Yki}^{\mathrm{S} 168 \mathrm{~A}}+\mathrm{Yki}$ $\mathrm{Yki}^{\mathrm{S} 168 \mathrm{~A}}+\mathrm{Yki}^{\mathrm{S} 168 \mathrm{~A}}$
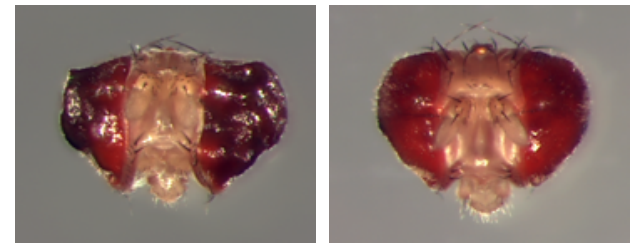

Fig. 5. Yki1 isoform can compete with Yki2 isoform in the nucleus.

a, Phenotypes induced by overexpression of $\mathrm{Yki}$ isoforms in the eye under the control of the GMR-Gal4 driver.

b, Co-overexpression of Yki isoforms using GMR-Gal4 driver. 

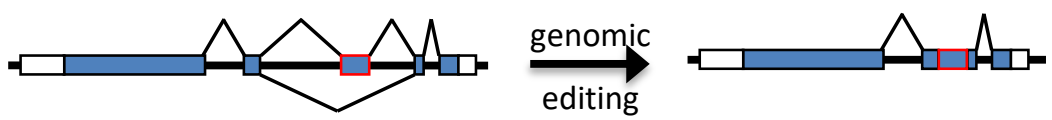

b

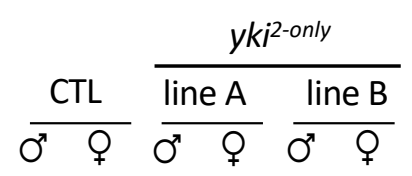

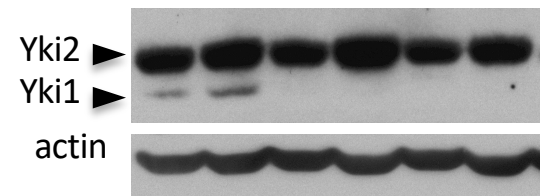

C

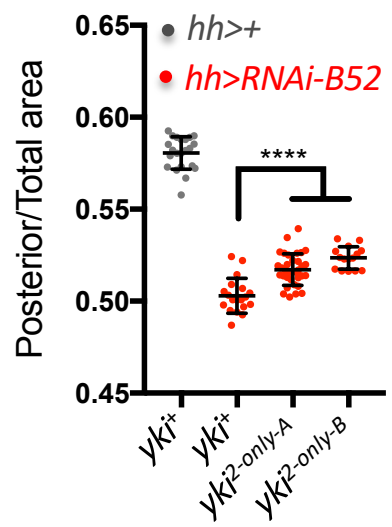

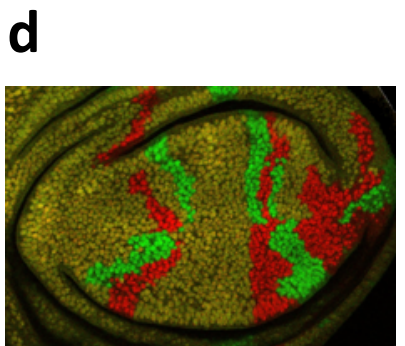

WT / WT

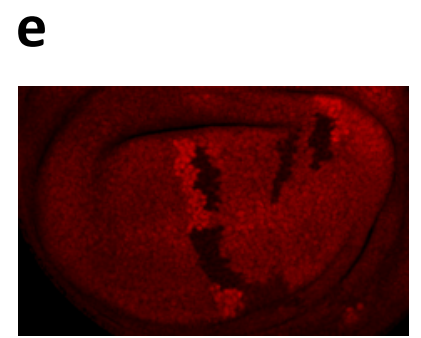

$y k i^{2-o n l y-A} / \mathrm{WT}$
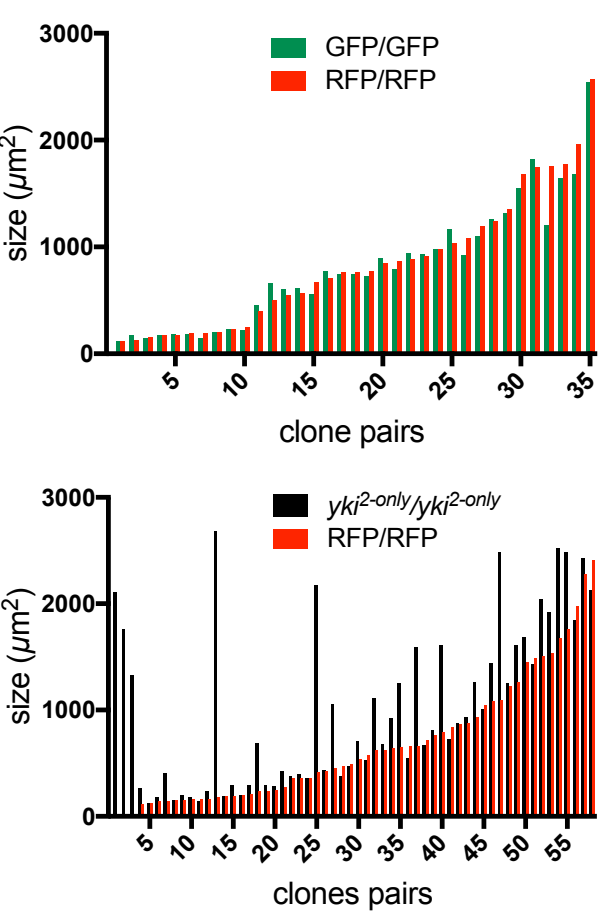

Fig. 6. Absence of $y k i$ alternative splicing reduces the phenotype of B52 depletion in the wing and favors clonal growth.

a, Structure of the $y k^{i 2-o n l y}$ allele compared to wild type $y k i$ locus. Introns surrounding exon 3 are removed. This allele does not contain any exogenous sequence. $\mathbf{b}$, Western blot of adult males and females showing disappearance of Yki1 isoform in the two $y k^{i 2-o n l y ~ f l y ~}$ lines. c, Comparison of posterior/total area ratio of females wings upon depletion of B52 in a $y \mathrm{ki}^{+}$(wild type) or $y \mathrm{ki}^{2-o n l y}$ background. Each point corresponds to a single wing, bars represent mean with SD (t-tests: $* * * *$ p-value $<0.0001$ ). d,e, Quantification of sibling clones size in the wing pouch. In $\mathbf{d}$, sibling wild-type clones are labelled with 2xGFP and 2xRFP. In e, unlabelled clones are homozygous for the $y k^{2-o n l y-A}$ allele whereas sibling clones (RFP/RFP) are wild type. In both graphs, clones pairs are sorted according to RFP/RFP clones size. 
a

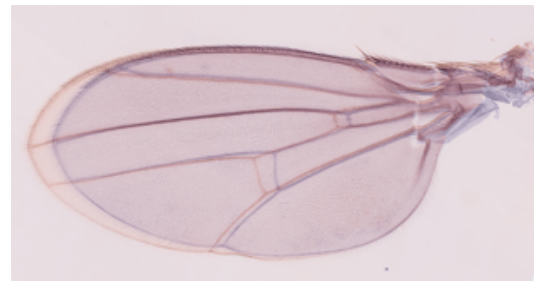

C

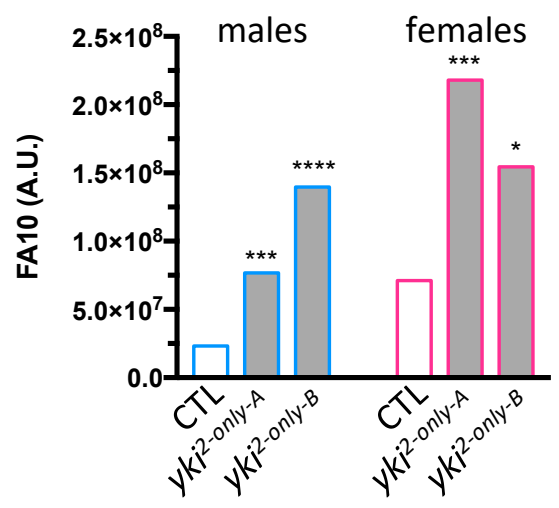

b
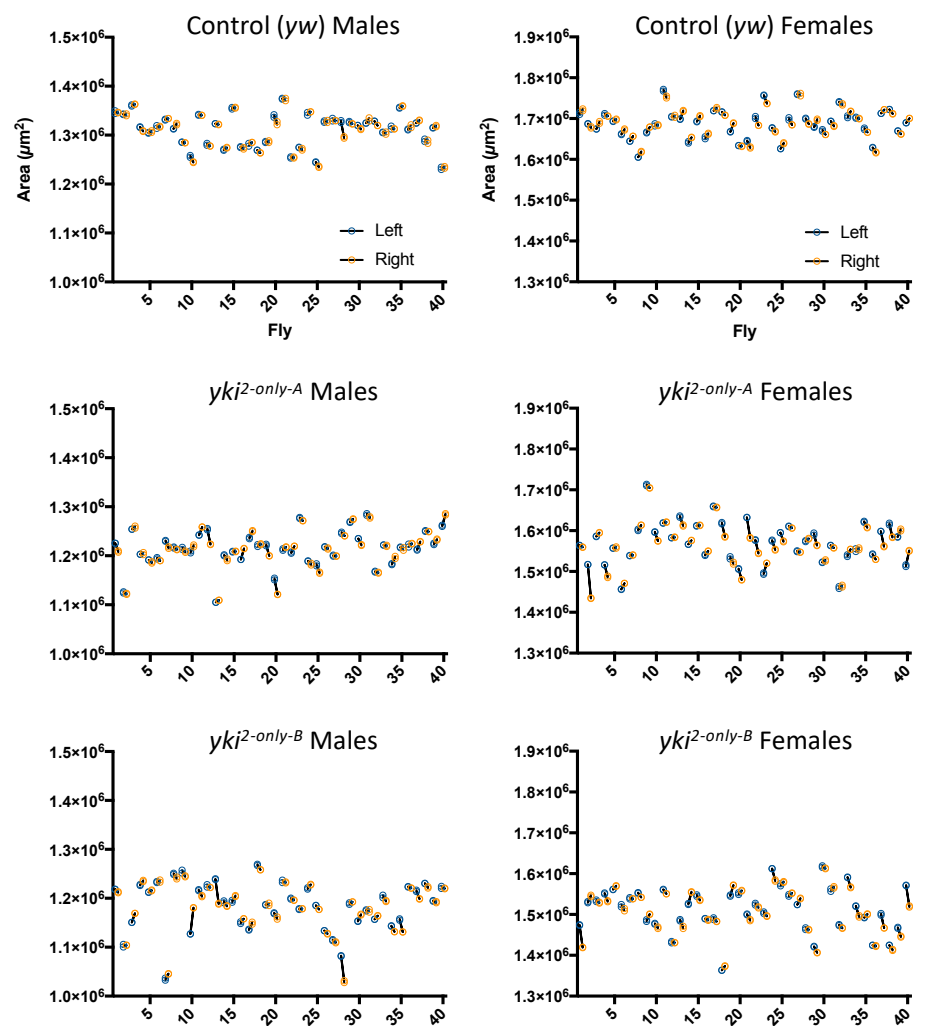

Fig. 7. Absence of $y k i$ alternative splicing increases developmental instability.

a, Overlay of right and left wings of a $y k^{2} i^{2-o n l y-A}$ female showing fluctuating asymmetry.

b, Distribution of wing size and wing asymmetry among the analyzed flies. Each circle represents the area of a single wing. Each wing was measured in duplicate. The difference between Right (orange) and Left (blue) sides of a single fly is schematized by a black line.

c, Quantification of fluctuating asymmetry index FA10 in control $(y w), y k i^{2-o n l y-A}$ and $y k i^{2-o n l y-B}$ flies ( $n=40)$ (F-tests: * $p$-value<0.05; *** p-value<0.001; **** $p$-value<0.0001). 


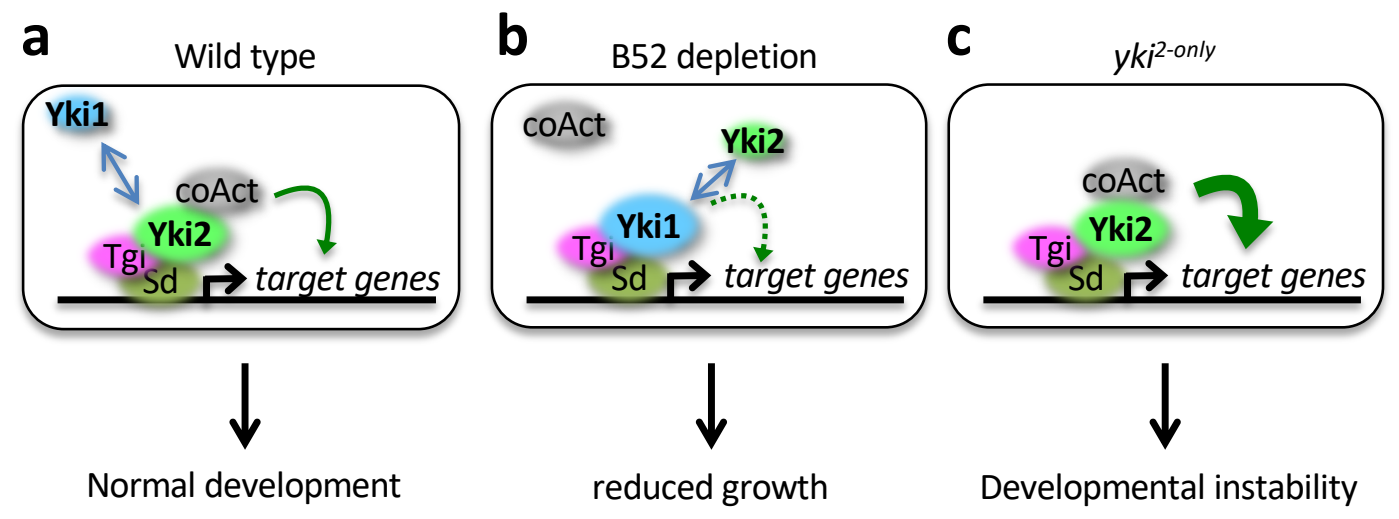

Fig. 8. Model of competition between Yki isoforms. See text. 

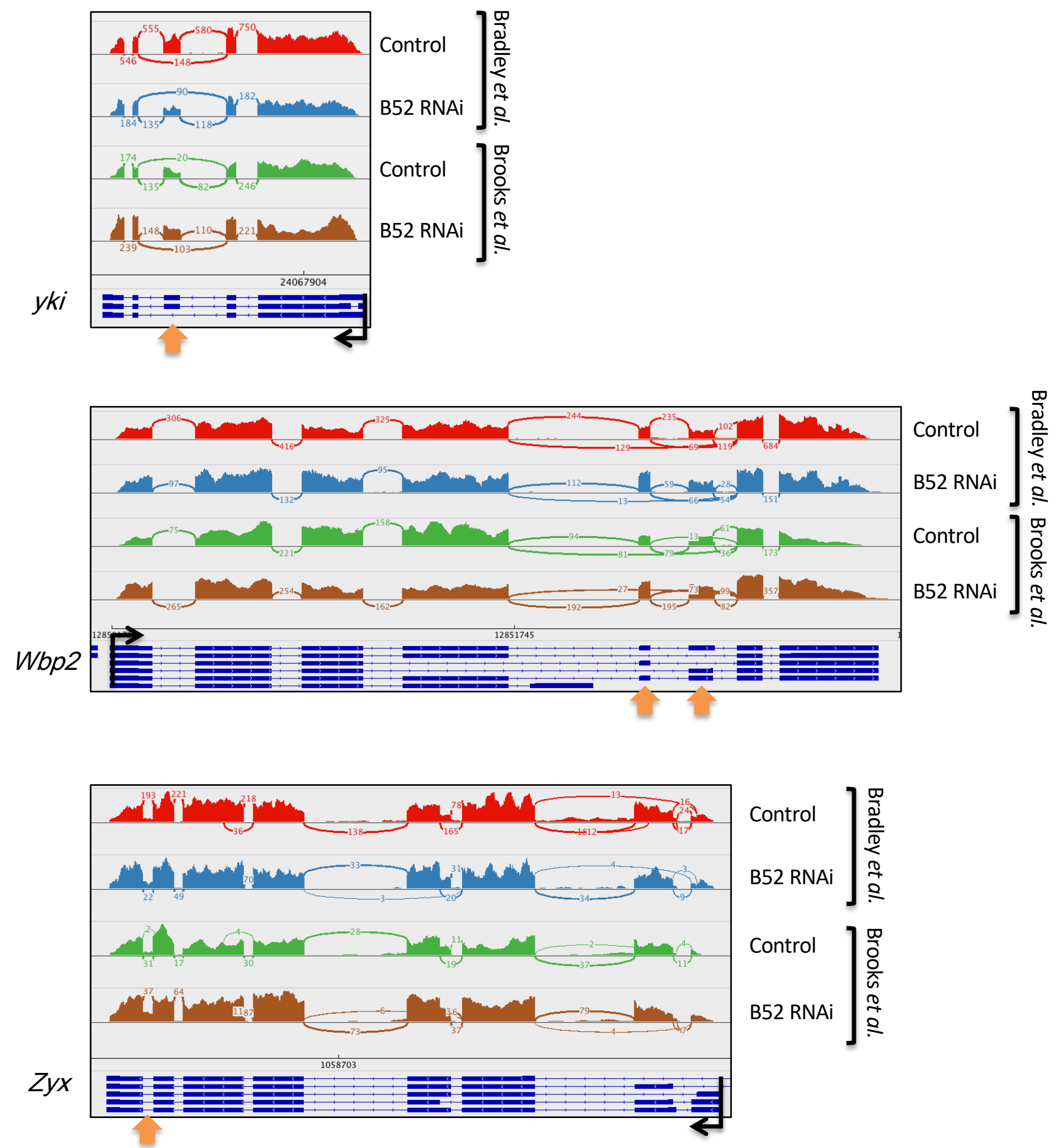

Supplementary Figure 1. Alternative splicing events modulated by B52 depletion in three genes linked to the Hippo pathway. The Sashimi plots illustrate the alternative splicing variation observed upon B52 depletion in yorkie (yki), WW domain-binding protein-2 (Wbp2) and Zyxin (Zyx) in the two datasets. The alternative exons or intron retention are indicated by the orange arrows. Black arrows represent transcription start site. 


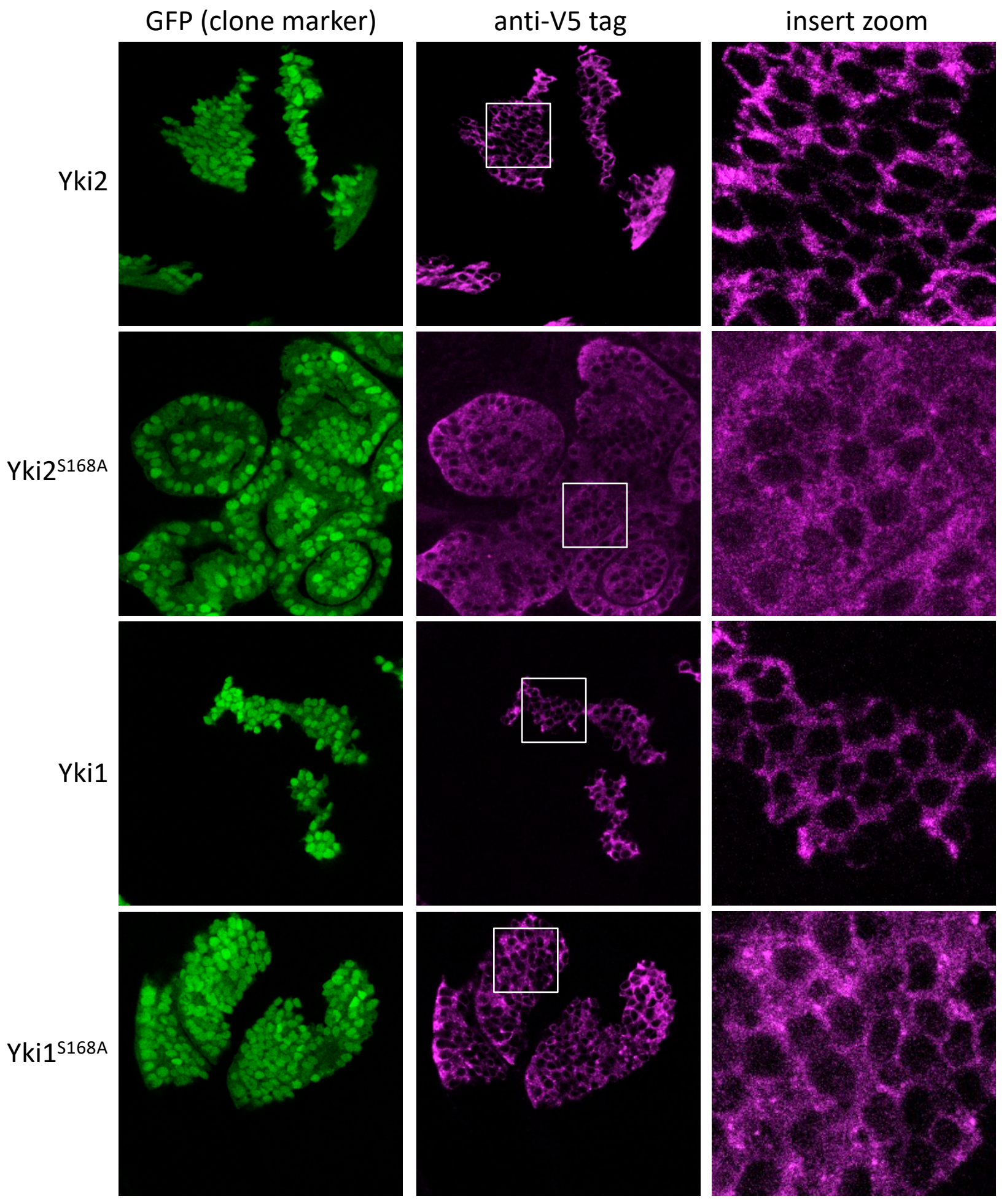

Supplementary Figure 2. Subcellular localization of Yki isoforms in overexpression clones in wing discs (flip-out clones).

Clones are labelled with GFP. Yki proteins are visualized with V5-tag fused to each isoform. 

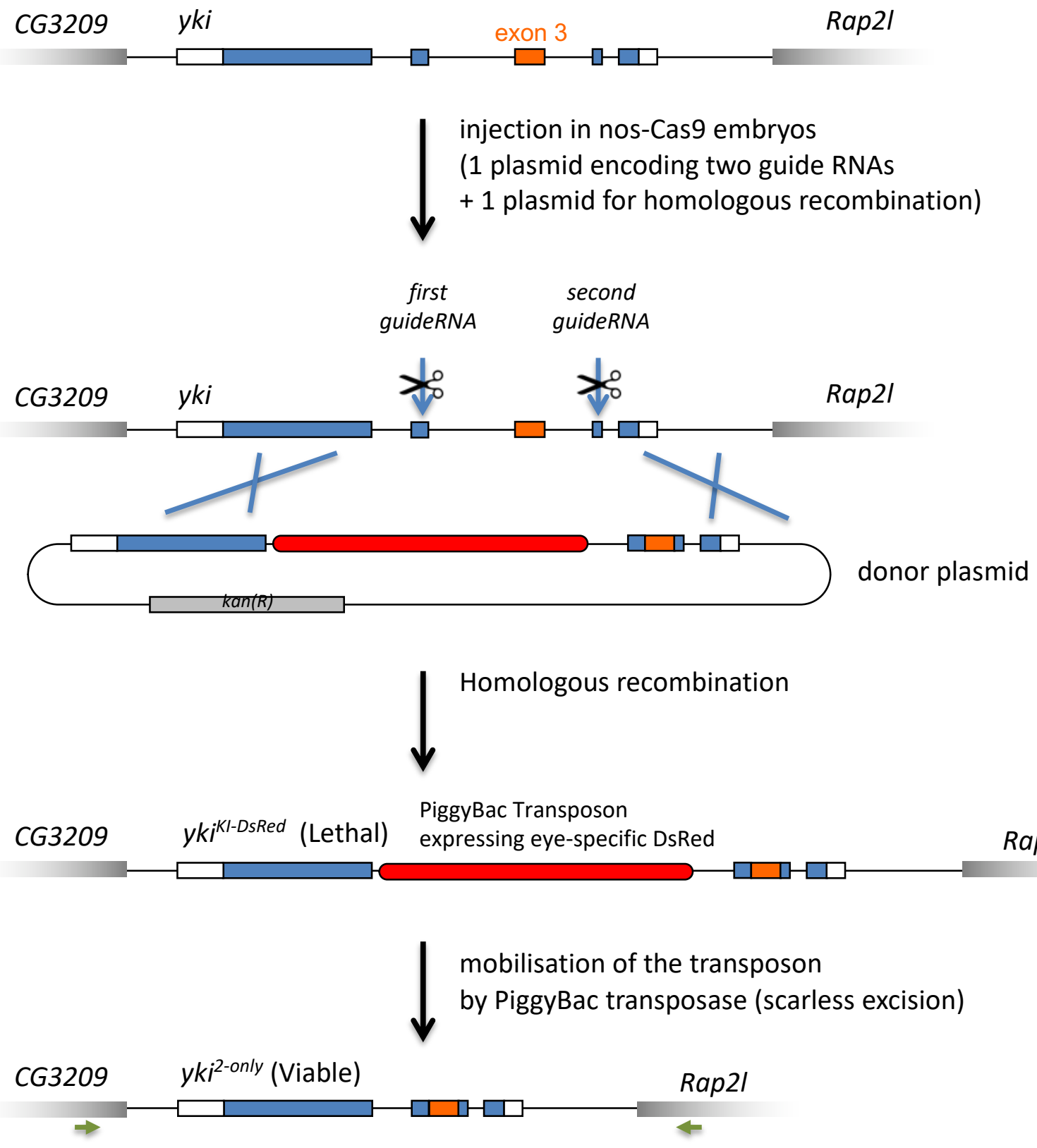

Supplementary Figure 3. Strategy used to create $\mathbf{y k j}^{\mathbf{2}-\text {-only }}$ allele. A donor plasmid was first assembled and cloned in bacteria. It contains the entire $y k i$ locus deleted for introns 2 and 3 and a PiggyBac transposon, carrying a eye-specific DsRED maker, inserted in the first intron. This construct was used as template for gene conversion after induction of double strand breaks in $y k i$ locus at the level on exons 2 and 4. Following injection in Cas9-expressing embryos, DsRED positive F1 flies were recovered and analyzed molecularly. Flies carrying the PiggyBac insertion in yki locus were not viable. Upon excision of the PiggyBac by a transposase provided in trans, non-DsRED flies were recovered. These flies were viable and correspond to the $y k^{2-o n l y}$ allele. Two independent lines ( $\mathrm{A}$ and $\mathrm{B}$ ) corresponding to two independent recombination events, were analyzed. The entire locus was sequenced in these lines. We noticed few polymorphism between the two lines, in introns and silent polymorphism in exons. These polymorphisms are present in the parental lines $y w$, used to create the repair construct, and nos-Cas9, in which injection was made. The positions of most distal primers used to sequence the locus are shown (green arrows). 
a
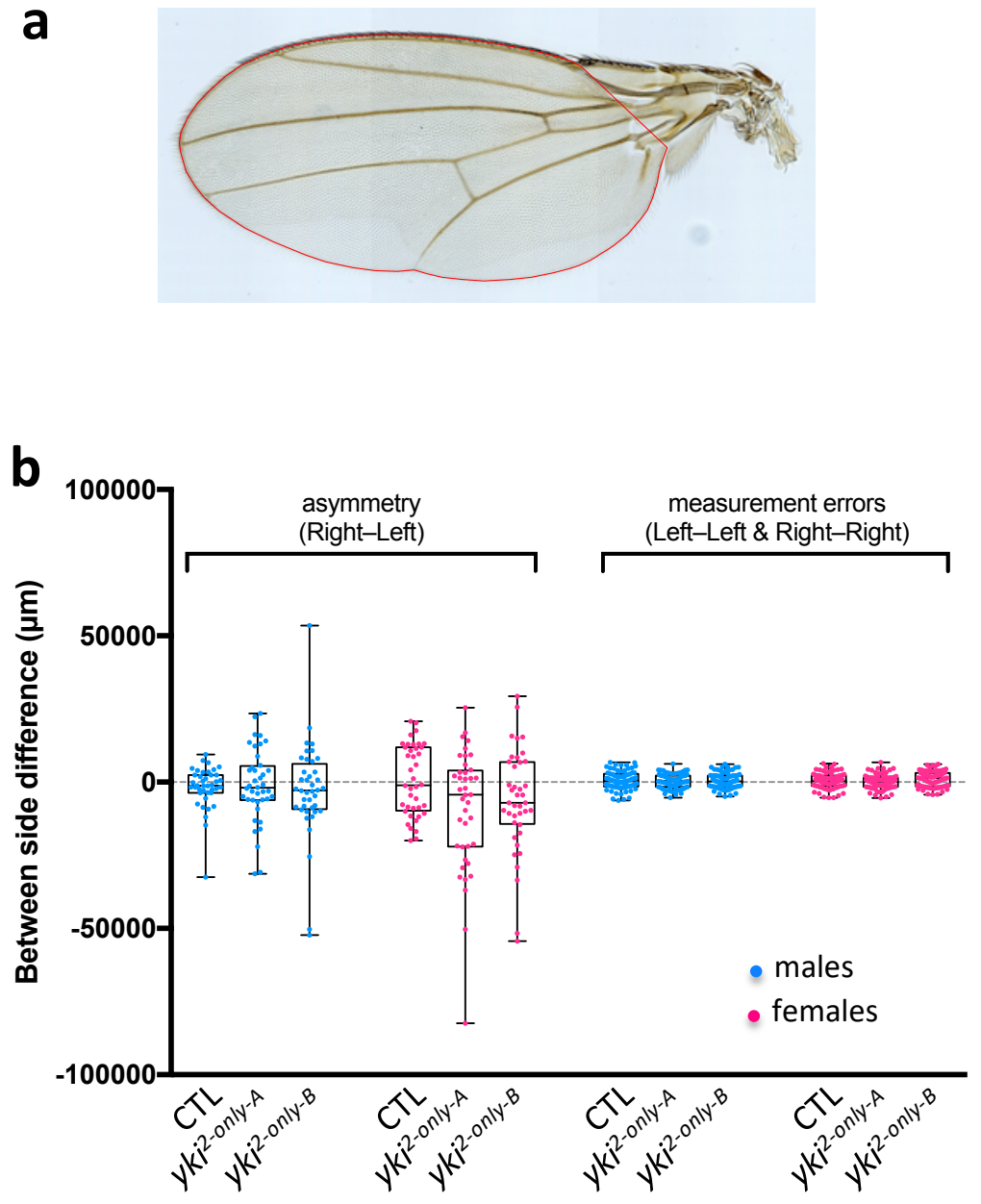

Supplementary Figure 4. Quantification of fluctuating asymmetry. a, Illustration of the domain used to quantify wing area (red line). Each wing was measured twice. b, Box plot of Right-Left difference compared to Measurement Errors (corresponding to the difference in replicate measurements). $n=40$ flies for each genotype. 
bioRxiv preprint doi: https://doi.org/10.1101/2019.12.19.882779; this version posted December 20, 2019. The copyright holder for this preprint (which was not certified by peer review) is the author/funder. All rights reserved. No reuse allowed without permission.

\begin{tabular}{|c|c|}
\hline Symbol & Full name \\
\hline$A b i$ & Abelson interacting protein \\
\hline Acn & Acinus \\
\hline Akap200 & A kinase anchor protein 200 \\
\hline Aldh-III & Aldehyde dehydrogenase type III \\
\hline Ate1 & Arginyltransferase 1 \\
\hline Atg16 & Autophagy-related 16 \\
\hline Atg18a & Autophagy-related $18 a$ \\
\hline bip2 & bip2 \\
\hline Caper & Caper \\
\hline Caper & Caper \\
\hline cert & ceramide transfer protein \\
\hline CG11753 & - \\
\hline CG13124 & - \\
\hline CG13366 & - \\
\hline CG1578 & - \\
\hline CG1578 & - \\
\hline CG1620 & - \\
\hline CG17724 * & - \\
\hline CG2519 & - \\
\hline CG3065 & - \\
\hline CG31855 & - \\
\hline CG32344 & - \\
\hline CG3760 & - \\
\hline CG41378 & - \\
\hline CG4281 & - \\
\hline CG5746 & - \\
\hline CG6084 & - \\
\hline CG6171 & - \\
\hline CG7028 & - \\
\hline CG7879 & - \\
\hline CG7974 & - \\
\hline CG8765 & - \\
\hline CG9684 & - \\
\hline CG9705 & - \\
\hline ctrip & circadian trip \\
\hline Cul2 & Cullin 2 \\
\hline CycG & Cyclin $G$ \\
\hline Dap160 & Dynamin associated protein 160 \\
\hline$D g$ & Dystroglycan \\
\hline dlg1 & discs large 1 \\
\hline$E(z)$ & Enhancer of zeste \\
\hline$E 2 f 1$ & E2F transcription factor 1 \\
\hline east & enhanced adult sensory threshold \\
\hline elF4B & eukaryotic translation initiation factor $4 B$ \\
\hline elF4E1 & eukaryotic translation initiation factor $4 E 1$ \\
\hline Fer1HCH & Ferritin 1 heavy chain homologue \\
\hline Flo2 & Flotillin 2 \\
\hline Gdh & Glutamate dehydrogenase \\
\hline hdly & hadley \\
\hline HipHop & HP1-HOAP-interacting protein \\
\hline HIPP1 & HP1 and insulator partner protein 1 \\
\hline Jupiter & Jupiter \\
\hline$K d m 4 B *$ & Lysine (K)-specific demethylase $4 B$ \\
\hline kis & kismet \\
\hline kuz & kuzbanian \\
\hline l(2)k09913 & lethal (2) k09913 \\
\hline Mef2 & Myocyte enhancer factor 2 \\
\hline mib2 & mind bomb 2 \\
\hline Mkrn1 & Makorin 1 \\
\hline Mlf & Myelodysplasia/myeloid leukemia factor \\
\hline MP1 & Melanization Protease 1 \\
\hline$m r i$ & mrityu \\
\hline$m t d$ & mustard \\
\hline NC73EF & Neural conserved at $73 E F$ \\
\hline ND-15 & NADH dehydrogenase (ubiquinone) $15 \mathrm{kDa}$ subunit \\
\hline ND-MWFE & NADH dehydrogenase (ubiquinone) MWFE subunit \\
\hline Nipped-B & Nipped-B \\
\hline nolo & no long nerve cord \\
\hline$p 24-2+$ & p24-related-2 \\
\hline Pdhb & Pyruvate dehydrogenase E1 beta subunit \\
\hline Pect & Phosphoethanolamine cytidylyltransferase \\
\hline Pep & Protein on ecdysone puffs \\
\hline
\end{tabular}

\begin{tabular}{|c|c|c|}
\hline Chr. & Strand & $\begin{array}{l}\text { AS event favoured by B52 depletion } \\
\text { exon skipning }\end{array}$ \\
\hline $2 \mathrm{~L}$ & + & intron retention \\
\hline $2 \mathrm{~L}$ & + & intron retention \\
\hline $2 \mathrm{R}$ & - & intron removal \\
\hline $2 \mathrm{R}$ & - & exon inclusion \\
\hline $3 R$ & - & upstream 3' ss \\
\hline $3 \mathrm{~L}$ & + & intron retention \\
\hline 4 & - & intron retention \\
\hline $2 \mathrm{~L}$ & + & intron retention \\
\hline $2 \mathrm{~L}$ & + & downstream 3'ss (multiple exons skipping) \\
\hline $3 \mathrm{~L}$ & - & exon skipping \\
\hline $3 R$ & + & intron retention \\
\hline $2 \mathrm{~L}$ & - & exon skipping \\
\hline$x$ & - & exon skipping \\
\hline$x$ & - & exon skipping \\
\hline$x$ & - & exon skipping \\
\hline $2 \mathrm{R}$ & - & intron retention \\
\hline $2 \mathrm{R}$ & - & exon inclusion \\
\hline $3 R$ & - & intron retention \\
\hline $2 \mathrm{R}$ & + & intron retention \\
\hline $2 \mathrm{~L}$ & + & intron retention \\
\hline $3 \mathrm{~L}$ & - & upstream 3' ss \\
\hline $2 \mathrm{R}$ & + & upstream 3' ss \\
\hline $2 \mathrm{R}$ & - & exon skipping \\
\hline$x$ & - & intron retention \\
\hline $3 R$ & - & intron retention \\
\hline $3 \mathrm{~L}$ & - & exon skipping \\
\hline $3 R$ & - & intron retention \\
\hline $3 \mathrm{~L}$ & - & intron retention \\
\hline $3 \mathrm{~L}$ & - & exon skipping \\
\hline $3 L$ & + & intron removal \\
\hline $3 \mathrm{~L}$ & - & distal 5'ss and 3'ss + exons skipping \\
\hline $3 R$ & - & intron retention \\
\hline $3 L$ & + & intron retention \\
\hline $3 R$ & - & inclusion of two consecutive exons \\
\hline $2 \mathrm{~L}$ & + & intron removal (two 5'ss) \\
\hline $3 R$ & - & upstream 3'ss \\
\hline $2 \mathrm{~L}$ & - & exon skipping \\
\hline $2 \mathrm{R}$ & - & exon inclusion \\
\hline$x$ & + & exon inclusion \\
\hline $3 \mathrm{~L}$ & - & exon inclusion \\
\hline $3 R$ & - & intron retention \\
\hline$x$ & + & intron retention \\
\hline $3 \mathrm{~L}$ & - & exon skipping \\
\hline $3 \mathrm{~L}$ & - & downstream 3'ss + exon skipping \\
\hline $3 R$ & - & downstream 3'ss \\
\hline$x$ & + & exon inclusion \\
\hline $3 R$ & - & exon inclusion \\
\hline $3 R$ & + & exon skipping \\
\hline $3 \mathrm{~L}$ & + & intron retention \\
\hline $3 L$ & + & intron retention \\
\hline $3 R$ & - & mutliple exon skipping \\
\hline $2 R$ & - & exon inclusion \\
\hline $2 \mathrm{~L}$ & - & exon skipping \\
\hline $2 \mathrm{~L}$ & + & exon inclusion \\
\hline $2 \mathrm{R}$ & + & downstream 3'ss + multiple exon skipping \\
\hline $2 \mathrm{R}$ & - & exon skipping \\
\hline $2 \mathrm{~L}$ & + & exon skipping \\
\hline $3 L$ & - & exon inclusion (two upstream 3'ss) \\
\hline $2 \mathrm{R}$ & - & exon inclusion \\
\hline $3 R$ & + & intron retention \\
\hline $3 L$ & + & intron retention \\
\hline $3 R$ & - & alternative first exon \\
\hline $3 \mathrm{~L}$ & + & downstream mutually exclusive exon \\
\hline $2 \mathrm{~L}$ & + & intron retention \\
\hline $2 \mathrm{R}$ & + & upstream terminal exon \\
\hline $2 \mathrm{R}$ & - & upstream alternative 5'ss \\
\hline $2 \mathrm{~L}$ & + & micro-exon inclusion \\
\hline $3 R$ & - & exon skipping \\
\hline $3 R$ & + & intron retention \\
\hline $2 \mathrm{~L}$ & + & upstream 3'ss \\
\hline $3 \mathrm{~L}$ & - & exon inclusion \\
\hline
\end{tabular}

\section{Coordinates}

14120611 - 14120622

19046142 - 19046207

8428068 - 8428319

$7473844-7473915$

20255886 - 20256035

$29832372 / 29832348$ - 29833193

8189969 - 8190072

$460141-460203$

7032840 - 7032903

7033018 - 7034199/7035407

8289170 - 8289483

$8653286-8653355$

$9905138-9905291$

$610549-611341$

$11814697-11814881$

11811652 - 11812603

7494798 - 7494865

$13179588-13180110$

$5541494-5541553$

$23970594-23970652$

$13369324-13369385$

$321549 / 321363-321915$

24938842 - 24938956/24938956

$2830708-2831043$

2064821 - 2064873

$24347595-24347663$

$11620923-11621103$

15363098 - 15363151

$210399-210476$

$1568197-1568309$

$1666367-1666554$

$19686399 / 19686646$ - 19687176/19687148

$8360247-8360300$

$16780421-16780504$

4796489 - 4797697 and 4795737 - 4795823

21658854/21658961 - 21659095

$31602230 / 31603073$ - 31610881

$21138113-21138361$

$16086931-16087725$

$11400788-11400832$

$10636426-10636440$

$21626625-21626691$

$2021118-2021171$

$27847425-27847485$

$9401367 / 9400953-9402280$

$30387602 / 30387550$ - 30387775

14925646 - 14925684

$23936981-23937019$

$20927188-20927466$

$18821250-18821306$

20812468 - 20812523

$11591307-11593633$

$13179588-13180110$

$229173-229382$

$13636384-13636843$

23067307 - 23067632/23070607

9940745 - 9940953

19037804 - 19037971

21531644 - 21531683/21531664

$15936580-15937326$

$4308427-4308620$

201758 - 201817

$5297313-5297516$

16960538 - 16960667 vs 16961500 - 16961602 $155429-155567$

13159534 - 13159649 vs $13159731-13160190$

4695610 - 4698503/4699059/4700389

$21726001-21726008$

$9688536-9688621$

29113141 - 29113207

13208777 - 13209436/13209472

17643979 - 17644079 
bioRxiv preprint doi: https://doi.org/10.1101/2019.12.19.882779; this version posted December 20, 2019. The copyright holder for this preprint (which was not certified by peer review) is the author/funder. All rights reserved. No reuse allowed without permission.

$\begin{array}{ll}\text { Pgam5 } & \text { Phosphoglycerate mutase 5 } \\ \text { PGAP5 } & \text { Post-GPI attachment to proteins 5 } \\ \text { Phb2 } & \text { Prohibitin 2 } \\ \text { Phb2 } & \text { Prohibitin 2 } \\ \text { PMCA } & \text { plasma membrane calcium ATPase } \\ \text { Rad23 } & \text { Rad23 } \\ \text { Rala } & \text { Ras-like protein A } \\ \text { rdx } & \text { roadkill } \\ \text { rin } & \text { rasputin } \\ \text { rl } & \text { rolled } \\ \text { RpS21 } & \text { Ribosomal protein S21 } \\ \text { rush } & \text { rush hour } \\ \text { SelR } & \text { Selenoprotein } R \\ \text { seq } & \text { sequoia } \\ \text { shi } & \text { shibire } \\ \text { Sodh-2 } & \text { Sorbitol dehydrogenase-2 } \\ \text { sol } & \text { small optic lobes } \\ \text { spi } & \text { spitz } \\ \text { spz } & \text { spatzle } \\ \text { stas } & \text { Stasimon } \\ \text { Sting } & \text { Sting } \\ \text { Su(z)12 } & \text { Su(z)12 } \\ \text { tacc } & \text { transforming acidic coiled-coil protein } \\ \text { Taf12 } & \text { TBP-associated factor 12 } \\ \text { teq } & \text { Tequila } \\ \text { Tif-IA } & \text { Tif-IA } \\ \text { tou } & \text { toutatis } \\ \text { Trs23 } & \text { TRAPP subunit 23 } \\ \text { Unc-115b }+ & \text { Uncoordinated 115b } \\ \text { unc-13 } & \text { unc-13 } \\ \text { Usp2 } & \text { Ubiquitin specific protease 2 } \\ \text { Vha100-1 } & \text { Vacuolar H[+] ATPase 100kD subunit 1 } \\ \text { vtd } & \text { verthandi } \\ \text { Wbp2 } & \text { WW domain binding protein 2 } \\ \text { yki } & \text { yorkie } \\ \text { Zyx } & \text { Zyxin } \\ & \end{array}$

$\begin{array}{cll}X & - & \text { intron retention } \\ 2 \mathrm{~L} & + & \text { intron retention } \\ 2 \mathrm{R} & + & \text { intron retention } \\ 2 \mathrm{R} & + & \text { upstream poly(A) site use } \\ 4 & - & \text { skipping of } 2 \text { consecutive exons } \\ 4 & + & \text { exon skipping } \\ \mathrm{X} & - & \text { exon skipping } \\ 3 \mathrm{R} & - & \text { alternative first exon } \\ 3 \mathrm{R} & + & \text { upstream } 5 \text { 'ss } \\ 2 \mathrm{R} & + & \text { exon skipping } \\ 2 \mathrm{~L} & + & \text { intron removal } \\ \mathrm{X} & + & \text { intron retention } \\ 3 \mathrm{R} & - & \text { upstream } 3 \text { 'ss } \\ 2 \mathrm{R} & - & \text { inclusion of } 2 \text { consecutive exons } \\ \mathrm{X} & + & \text { exon inclusion } \\ 3 \mathrm{R} & + & \text { intron retention } \\ \mathrm{X} & + & \text { downstream } 5 \text { 'ss } \\ 2 \mathrm{~L} & - & \text { exon skipping } \\ 3 \mathrm{R} & - & \text { exon skipping } \\ \mathrm{X} & - & \text { intron retention } \\ 2 \mathrm{R} & + & \text { intron retention } \\ 3 \mathrm{~L} & - & \text { exon skipping } \\ 3 \mathrm{R} & - & \text { alternative first exon } \\ 3 \mathrm{R} & - & \text { exon inclusion } \\ 3 \mathrm{~L} & + & \text { skipping of } 9 \text { consecutive exons } \\ 2 \mathrm{~L} & + & \text { skipping of } 2 \text { consecutive exons } \\ 2 \mathrm{R} & - & \text { intron retention } \\ 2 \mathrm{~L} & + & \text { intron retention } \\ 3 \mathrm{R} & - & \text { exon skipping } \\ 4 & - & \text { skipping of } 3 \text { consecutive exons } \\ \mathrm{X} & + & \text { exon inclusion } \\ 3 \mathrm{R} & + & \text { exon inclusion } \\ 3 \mathrm{~L} & + & \text { skipping of } 2 \text { or } 4 \text { consecutive exons } \\ 3 \mathrm{~L} & + & \text { inclusion of } 2 \text { consecutive exons } \\ 2 \mathrm{R} & - & \text { exon skipping } \\ 4 & - & \text { intron retention } \\ & & \end{array}$

\begin{tabular}{|c|}
\hline $1872907-1872972$ \\
\hline $8200281-8200345$ \\
\hline $18821284-18821489$ \\
\hline $18821489 / 18822250$ \\
\hline $351586-351827$ and $351586-351827$ \\
\hline 308431 - 309079 \\
\hline $3707368-3707491$ \\
\hline $13981634-13983363$ \\
\hline $13647200 / 13647546-13648918$ \\
\hline $1113537-1113725$ \\
\hline $2856569-2856630$ \\
\hline $1480874-1481007$ \\
\hline $10863858 / 10863825-10866529$ \\
\hline $13180990-13183234$ and $13179588-13180110$ \\
\hline 15899444 - 15899455 \\
\hline 10877648 - 10877701 \\
\hline $21353063 / 21353665-21354094$ \\
\hline 19571572 - 19571767 \\
\hline $27067358-27067495$ \\
\hline 17627088 - 17627167 \\
\hline $9844904-9844990$ \\
\hline 19919359 - 19919520 \\
\hline $4739511-4739547$ \\
\hline $11679354-11679398$ \\
\hline $9075622-9087849$ \\
\hline $22250853-22257653$ \\
\hline $11580863-11580948$ \\
\hline $8686493-8686549$ \\
\hline $9688536-9688621$ \\
\hline $877194-882961$ \\
\hline $22462400-22463272$ \\
\hline $29134557-29134598$ \\
\hline $27140242-27146945$ or $27140242-27156010$ \\
\hline $12852232-12852277$ and $12852427-12852528$ \\
\hline $24066561-24066716$ \\
\hline $1057573-1057632$ \\
\hline
\end{tabular}

Supplementary Table 1. Comprehensive list of Alternative Splicing (AS) events modulated by B52 depletion in S2 cells. AS events were identified based on Local Splicing Variation (LSV) of more than $20 \%$ between control cells and B52-depleted cells, in the two datasets of Bradley et al. (2015) and Brooks et al. (2015). Each event was manually annotated to provide a straightforward list of high confidence AS events. The coordinates (based on Dm6.19) correspond to exon boundaries in case of single exon skipping or single exon inclusion, and correspond to intron boundaries in case of intron retention, intron removal, and skipping of multiple exons. Alternative sites are separated by "/". Symbols * and + denote two groups of overlapping genes containing shared exons. 


\begin{tabular}{|c|c|c|}
\hline Figure Panel & Genotypes & Sex \\
\hline \multirow[t]{2}{*}{$1 f$} & w, MS1096-Gal4 & M \\
\hline & W, MS1096-Gal4; UAS-IR-B52 $2^{G D 8690 /+}$ & M \\
\hline \multirow[t]{2}{*}{$2 a$} & $y, w ; h h-G a l 4$, UAS-GFP/+ & $\mathrm{F}$ \\
\hline & $y, w ;$ hh-Gal4, UAS-GFP/UAS-IR-B52 ${ }^{G D 8690}$ & $\mathrm{~F}$ \\
\hline \multirow[t]{12}{*}{$2 b, c$} & $y, w ; h h-G a l 4 /+$ & M \\
\hline & $y, w ; h h-G a l 4$, UAS-IR-B52 $2^{G D 8690} /+$ & M \\
\hline & $y, w ; h h-G a l 4 /+;$ UAS-Yki-V5/+ & M \\
\hline & y, w; hh-Gal4, UAS-IR-B52 $2^{G D 8690 /+; ~ U A S-Y k i-V 5 /+~}$ & M \\
\hline & $y, w ; h h-G a l 4 /+;$ UAS-Yki.V5.O/+ & M \\
\hline & y, w; hh-Gal4, UAS-IR-B52 ${ }^{G D 8690} /+;$ UAS-Yki.V5.O/+ & M \\
\hline & $y, w ; h h-G a l 4 /+; U A S-I R-W t^{T R i P . H M S 00026} /+$ & M \\
\hline & y, w; hh-Gal4, UAS-IR-B52 ${ }^{G D 8690} /+;$ UAS-IR-Wts ${ }^{\text {TRIP.HMS00026 }} /+$ & M \\
\hline & y, w; hh-Gal4/+; UAS-IR-Hpo TRiP.HMS00006/+ & M \\
\hline & y, w; hh-Gal4, UAS-IR-B52 $2^{G D 8690} /+;$ UAS-IR-Hpo ${ }^{T R i P . H M S 00006} /+$ & M \\
\hline & y, w; hh-Gal4/+; UAS-IR-Tgi ${ }^{T R I P . H M S 00981} /+$ & M \\
\hline & y, w; hh-Gal4, UAS-IR-B52 ${ }^{G D 8690} /+;$ UAS-IR-Tgi ${ }^{\text {TRiP.HMS00981 } /+}$ & M \\
\hline \multirow[t]{3}{*}{$3 a$} & $y, w ; h h-G a l 4 /+$ & $\mathrm{F}$ \\
\hline & $y, w ; h h-G a l 4 / U A S-Y k i 1$ & $\mathrm{~F}$ \\
\hline & $y, w ; h h-G a l 4 / U A S-Y k i 2$ & $\mathrm{~F}$ \\
\hline \multirow[t]{3}{*}{$3 b$} & $w / y, w ; e x^{697} /+; h h-G a l 4, U A S-G F P /+$ & $\mathrm{F}$ \\
\hline & $w / y, w ; e x^{697} /+; h h-G a l 4$, UAS-GFP/UAS-Yki1 & $\mathrm{F}$ \\
\hline & $w / y, w ; e x^{697} /+; h h-G a l 4$, UAS-GFP/UAS-Yki2 & $\mathrm{F}$ \\
\hline \multirow[t]{9}{*}{$3 c$} & $w / y, w ; e x^{697} /+;$ hh-Gal4, UAS-GFP/+ & $\mathrm{F}$ \\
\hline & $w / y, w ; e x^{697} /+;$ hh-Gal4, UAS-GFP/UAS-Yki1 & $\mathrm{F}$ \\
\hline & $w / y, w ; e x^{697} /+; h h-G a l 4$, UAS-GFP/UAS-Yki2 & $\mathrm{F}$ \\
\hline & $w / y, w ;$ diap1-LacZ/+ ; hh-Gal4, UAS-GFP/+ & $\mathrm{F}$ \\
\hline & $w / y, w ; \operatorname{diap1-LacZ/+} ;$ hh-Gal4, UAS-GFP/UAS-Yki1 & $\mathrm{F}$ \\
\hline & w/y, w; diap1-LacZ/+ ; hh-Gal4, UAS-GFP/UAS-Yki2 & $\mathrm{F}$ \\
\hline & $y$, w; ban-sensor/t; hh-Gal4, UAS-GFP/+ & $\mathrm{F}$ \\
\hline & y, w; ban-sensor/t; hh-Gal4, UAS-GFP/UAS-Yki1 & $\mathrm{F}$ \\
\hline & y, w; ban-sensor/t; hh-Gal4, UAS-GFP/UAS-Yki2 & $\mathrm{F}$ \\
\hline \multirow[t]{5}{*}{$5 a$} & $w ; G M R-G a l 4 /+$ & $\mathrm{M}$ \\
\hline & w; GMR-Gal4/+; UAS-Yki1/+ & M \\
\hline & w; GMR-Gal4/+; UAS-Yki1 $5168 A /+$ & $\mathrm{M}$ \\
\hline & w; GMR-Gal4/+; UAS-Yki2/+ & $\mathrm{M}$ \\
\hline & w; GMR-Gal4/+; UAS-Yki2 ${ }^{S 168 A} /+$ & $\mathrm{M}$ \\
\hline \multirow[t]{4}{*}{$5 b$} & $w ; G M R-G a l 4 /+$ & $\mathrm{M}$ \\
\hline & w; GMR-Gal4/+; UAS-Yki2 $168 A /+$ & M \\
\hline & w; GMR-Gal4/+; UAS-Yki1/UAS-Yki2 ${ }^{S 168 A}$ & $\mathrm{M}$ \\
\hline & w; GMR-Gal4/+; UAS-Yki1 ${ }^{S 168 A} / U A S-Y k i 2^{S 168 A}$ & M \\
\hline \multirow[t]{3}{*}{$6 b$} & $y, w(C T L)$ & $\mathrm{M} / \mathrm{F}$ \\
\hline & $y, w ; y k i^{2-o n l y-A}$ & $\mathrm{M} / \mathrm{F}$ \\
\hline & $y, w ; y k i^{2-o n l y-B}$ & $\mathrm{M} / \mathrm{F}$ \\
\hline \multirow[t]{3}{*}{$6 c$} & $y, w ; h h-G a l 4 /+$ & $\mathrm{F}$ \\
\hline & $y, w ; h h-G a l 4$, UAS-IR-B52 $2^{G D 8690} /+$ & $\mathrm{F}$ \\
\hline & $y, w ; y k i^{2-o n l y-A} ;$ hh-Gal4, UAS-IR-B52 $2^{G D 8690} /+$ & $\mathrm{F}$ \\
\hline
\end{tabular}




\begin{tabular}{|c|c|c|}
\hline & $y, w ; y k i^{2-o n l y-B} ;$ hh-Gal4, UAS-IR-B52 ${ }^{G D 8690} /+$ & $\mathrm{F}$ \\
\hline $6 d$ & $y, w, h s-F L P ; F R T 42 D, u b i-G F P / F R T 42 D$, ubi-RFP & $\mathrm{M} / \mathrm{F}$ \\
\hline $6 e$ & $y, w, h s-F L P ; F R T 42 D, y k i^{2-o n l y-A} / F R T 42 D, u b i-R F P$ & $\mathrm{M} / \mathrm{F}$ \\
\hline $7 a$ & $y, w ; y k i^{2-o n l y-A}$ & $\mathrm{~F}$ \\
\hline \multirow[t]{3}{*}{$7 b, c$} & $y, w(C T L)$ & $M \& F$ \\
\hline & $y, w ; y k i^{2-o n l y-A}$ & $M \& F$ \\
\hline & $y, w ; y k i^{2-o n l y-B}$ & $M \& F$ \\
\hline \multirow[t]{4}{*}{ S2 } & $y, w, h s-F L P / y, w, A c t[C D 2] G a l 4 ; U A S-G F P^{N L S} / U A S-Y k i 2$ & $\mathrm{~F}$ \\
\hline & $y, w, h s-F L P / y, w, A c t[C D 2] G a l 4 ;$ UAS-GFP ${ }^{N L S} / U A S-Y k i 2^{S 168 A}$ & $\mathrm{~F}$ \\
\hline & $y, w, h s-F L P / y, w, A c t[C D 2] G a l 4 ; U A S-G F P^{N L S} / U A S-Y k i 1$ & $\mathrm{~F}$ \\
\hline & $y, w, h s-F L P / y, w, A c t[C D 2] G a l 4 ; U A S-G F P^{N L S} / U A S-Y k i 1^{S 168 A}$ & $\mathrm{~F}$ \\
\hline S4a & $y, w$ & M \\
\hline \multirow[t]{3}{*}{ S4b } & $y, w(\mathrm{CTL})$ & $M \& F$ \\
\hline & $y, w ; y k i^{2-o n l y-A}$ & $M \& F$ \\
\hline & $y, w ; y k i^{2-o n l y-B}$ & $M \& F$ \\
\hline
\end{tabular}

Supplementary Table 2. List of genotypes used in each Figure panel. 